\title{
SEISMIC RESPONSE OF SOIL-PILE RAFT-STRUCTURE SYSTEM
}

\author{
Rajib SAHA, Sekhar Chandra DUTTA, Sumanta HALDAR \\ Indian Institute of Technology Bhubaneswar, Bhubaneswar-751013, India
}

Received 25 Mar 2012; accepted 16 Aug 2012

\begin{abstract}
This paper presents an initial effort to investigate seismic response of soil-pile raft-structure system considering soil-structure interaction effect. In general, structure and piled raft under seismic load are designed considering fixed base condition. However, soil flexibility may result significant changes in the response of soil-pile raft-structure system. The study considers one storey system consisting of a mass in the form of a rigid floor slab supported by four columns. The piles are modelled by beam-column element supported by laterally distributed springs and dampers. This simple model used in present study is adequately tuned to exhibit reasonably accurate dynamic characteristics while compared to the existing well accepted methodologies. The study shows that soil-structure interaction leads to considerable lengthening of period though the lateral shear in columns are not significantly changed. However, the shear in piles is significantly increased due to SSI effect as inertia of the considerable foundation mass contributes to this increase in shear of pile. Thus, neglecting SSI may lead to unsafe seismic design of piles. A parametric study encompassing feasible variations of parameters is made under spectrum consistent ground motion. Effect of uncertainty in the soil subgrade modulus on the pile and column response variability is also studied.
\end{abstract}

Keywords: piled raft, soil structure interaction, seismic base shear, fixed base, natural period, uncertainty.

\section{Introduction}

Structures are mostly considered fixed at base for seismic design. However, the recent researches recommend equivalent springs to account for the support flexibility at the base of the structure due to presence of foundation and soil. This approach is found to give satisfactory results for all feasible varieties of shallow foundations (Bhattacharya et al. 2004). Their study mainly highlights the seismic response of structures supported by shallow foundation only where lateral shear as well as bending in foundation element was found to be a very insignificant issue. While in case of structures supported by piled raft foundation, lateral shear in foundation elements under seismic design criteria is a crucial factor for successful performance of such systems during earthquake. However, limited studies are available on seismic response of structure incorporating the effect of soil flexibility, if foundation consists of raft supported on pile group.

In a soil-pile raft-structure system, fixed based assumption considers fixity at base level of superstructure for structural design. Hence, seismic design of structure and piled raft is performed by computing base shear of structure under fixed base condition. Soil-structure interaction (SSI) is often ignored in most of the analyses pertaining to its complexity in modelling of the system. In fact, normally it is assumed that the SSI reduces the design forces at least for medium to long period structures and thus the structure becomes over-safe if it is designed on the basis of fixed base assumption. However, few investigators (Mylonakis, Gazetas 2000) reported that such notion leads to an unsafe design and may even cause failure of the whole structure as is evident from the past earthquakes (e.g. 1995 Kobe earthquake; 1985 Mexico City earthquake). In reality, due to deformable characteristics of soil, foundation offers a partial fixity at structure base level and thereby alters natural period and response of the system. In fact, such flexibility and damping of soil results in inertial interaction during dynamic loading and seems to be the prime reason for change in dynamic characteristics and response of the system (FEMA 2005). Present study is aimed at studying the seismic behaviour of structure attributing inertial interaction only, as the kinematic interaction seems not to be considerable for piles embedded in soil of softer consistency as indicated in well accepted literature (FEMA 2005). Extensive research has been carried out pertaining to dynamic behaviour of soil-pile subjected to horizontal vibration incorporating SSI (e.g. Novak 1974; Nogami, Novak 1980; Novak, Aboul-Ella 1978; El Naggar, Novak 1996). Behaviour of soil-pile-structure system under dynamic load has also been documented in literature (e.g. Hall 1984; Gazetas 1984; Kaynia, Kausel 1991; Makris,

Corresponding author: Sekhar Chandra Dutta

E-mail:scdutta@iitbbs.ac.in 
Gazetas 1992; Badoni, Makris 1996; Boulanger et al. 1999). In the above studies closed form analytical solutions were developed to obtain pile response, taking into account the dynamic pile-soil interaction. However, studies pertaining to the effect of soil structure interaction on the response of soil-pile raft-structure system are rather limited. Gazetas (1984) has made a qualitative assessment of the response of soil-pile-structure system for a wide range of seismic load and pile parameters. The study indicates that pile-soilstructure interaction plays a major role in peak response at pile head. Gazetas et al. (1993), Makris and Gazetas (1992) presented a parametric study for pile groups considering soil-pile interaction. The study also reveals that the crossinteraction between the piles controls the dynamic response of pile group under seismic inertial loading at pile head. Guin and Banerjee (1998) investigated that the distribution of structural loading transferred to the pile changes considerably for a coupled soil-pile-structure under seismic load due to SSI. Boulanger et al. (1999) assessed validity of dynamic $p-y$ analysis in seismic soil-pile-structure interaction using dynamic centrifuge model tests. Yingcai (2002), Rovithis et al. (2009) analysed a coupled behaviour of soilpile-structure systems, which concludes that the fixed base assumption without SSI may lead to unrealistic response of the system.

Various design guidelines, such as, Indian standard (BIS 1893-Part-I 2002), United States standard (ATC 40 1996; FEMA 356 2000), European standard (Eurocode 8-Part 1 1998), and design guidelines for Japan (JSCE 2000) suggest adopting pseudo-static approach to design structure and foundation system. The abovementioned design standards also indicate to conduct soil-pilestructure design considering SSI; however, no explicit guidelines were recommended. Though limited numbers of studies pertaining to the effect of SSI on the response of soil-pile-structure system have been carried out, the change of design forces in structural and foundation elements are not explored in detail.

The objective of the present study is to highlight the effect of soil-structure interaction on seismic response of soil-pile raft-structure system for realistic variations of soil stiffness values, depth wise variation of soil properties, pile length to diameter ratios and fundamental natural periods of superstructure. The dynamic effect during seismic shaking is attempted to be captured considering an idealised one storey system supported by piled raft foundation. The piles are assumed to be supported laterally by compression-only distributed linear springs. In order to obtain dynamic responses of soil-pile raft-structure system, finite element approach (FEA) is adopted. Validation of the numerical model is conducted by comparing natural period of vibration of system considering SSI (Tssi) with respect to few well accepted analytical expressions (Veletsos, Meek 1974; Gazetas 1996; Maravas et al. 2007) of the same. A spectrum consistent seismic ground motion is used to obtain seismic responses of the systems. Seismic design forces are obtained considering structural fixity at base and incorporating soil flexibility encompassing various consistencies of soil medium, pile geometry and fundamental period of structure. A probabilistic approach is adopted to incorporate uncertainty in the value of subgrade modulus of soil. Variability in the responses of column and pile is determined and finally lower and upper bound values of responses are presented based on probabilistic approach. The study may provide crucial inputs in refining design guidelines of soil-pile raft-superstructure system. An example problem is also presented in order to explain the usefulness of incorporation of SSI while designing of structure supported on piled raft foundation.

\section{System modelling}

\subsection{Modelling of superstructure}

Seismic response of a fixed base superstructure is obtained by idealizing a one storey system to resemble a single storey of freedom (SDOF) system as a main focus of the paper. In order to verify the performance of such SDOF system, multi-degree of freedom (MDOF) idealization for structure is attempted in a limited form.

Superstructure is considered as three dimensional space frame structure which consists of four column members supporting a rigid deck slab. Structural fixed base condition is idealized by restraining all possible degrees of freedom at all column supports. To have an overview on the behaviour of multi-storey structures with various heights, representative periods, namely $0.25 \mathrm{sec}$, $0.50 \mathrm{sec}, 1.0 \mathrm{sec}$, and $2.0 \mathrm{sec}$ are considered, which represent typical short, medium and long period structure respectively. The fundamental period of superstructure is calculated by changing the mass of superstructure and lateral stiffness of column. Column stiffness is attributed by assigning suitable sectional properties. The superstructure is considered to be supported by a piled raft foundation designed on the basis of gravity loading. A schematic diagram of the idealized system for fixed base and soil-pile raft-structure is shown in Figure 1. To resemble a multi-degree freedom system (MDOF), a 4-storeyed building, which consists of four rigid deck slabs of uniform thickness supported by four column members at each storey is considered. Column stiffness is adjusted to derive a fundamental lateral period of $0.5 \mathrm{sec}$ under fixed base condition for this 4-storeyed building. SSI effect is examined by further modelling the raft, piles and lateral soil springs.

\subsection{Idealization of pile raft-soil system}

Pile raft-soil interaction consists of two aspects: (1) interaction between raft and soil; (2) interaction between pile and soil. The well accepted and adequate literature is used to derive the properties of springs, in both aspects. In fact, raft-soil spring action is modelled following a study on dynamic stiffness of shallow footing (Gazetas 1991). Further, pile-soil spring action is conceived through introducing distributed soil springs along the 


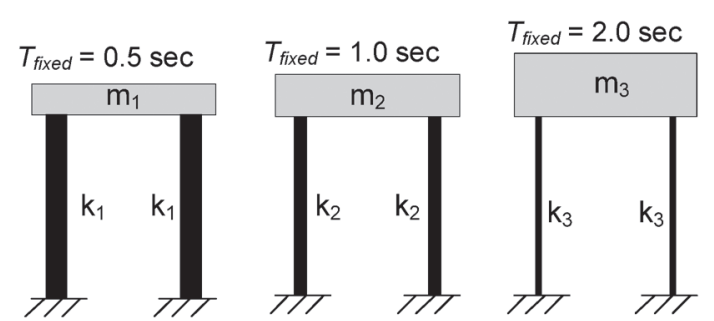

(a)

$\mathrm{m}_{1}, \mathrm{~m}_{2}, \quad \mathrm{~m}_{3}=$ Super structural masses assumed for different fixed base period of structures

$\mathrm{k}_{1}, \mathrm{k}_{2}, \mathrm{k}_{3}=$ Column stiffness assumed for respective structures

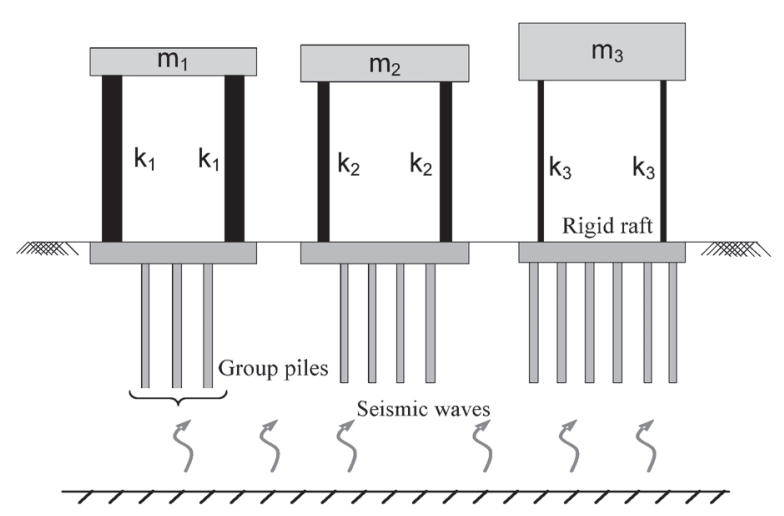

(b)

Fig. 1. Schematic diagram of the idealized system considered: a) fixed base system; b) the SSI system

length of pile as suggested in well accepted literature (Roesset, Angelides 1980; Gazetas, Dobry 1984; Makris, Gazetas 1992). These spring stiffness values primarily depend upon soil shear modulus which is an intrinsic property of soil. However, a validation pertaining to overall pile group raft - soil stiffness has been conducted through overall stiffness of pile group as suggested by Poulos (2001). It is observed that overall lateral stiffness of piled raft obtained from the present model is in good agreement with various empirical and analytical methods (e.g. Gazetas 1984; Dobry, Gazetas 1988; Makris, Gazetas 1992). Soil is considered to have a linear elastic behaviour with constant Poisson's ratio and constant mass density. Three different variations of soil subgrade modulus, $k_{h}(z)$ are obtained from three different variations of Young's modulus of soil, $E_{s}(z)$, as presented in Figure 2. The first soil model represents uniform $E_{s}(z)$ and hence, $k_{h}(z)$ with depth. Second model considers $E_{s}(z)$ as well as $k_{h}(z)$ proportional to depth, while $E_{s}(z)$ (or $k_{h}(z)$ ) follows a parabolic distribution in the third model. In fact, these models are suitable to cover the variation of properties in wide range of soil profiles as described in previous studies (e.g. Gazetas, Dobry 1984; Gazetas 1984). In order to examine the response of soil-pile raft-structure, three different soil stiffness values, namely very soft, soft, and moderately stiff are considered herein. In order to incorporate these three different profiles for a particular soil stiffness, a reference value of $E_{s d}$ (characteristic Young's modulus of soil) is considered at shallow depth (i.e. at one diameter of pile below ground level) as suggested by Gazetas (1984). Depth wise subgrade modulus (or stiffness) of soil are obtained based on $E_{s d}$ values. The reference values of $E_{s d}$ at $z=d$ are given in Table 3 . Such idealized profiles are considered to take care of the in-situ condition of a homogenous sub-soil layer in a more realistic sense. However, Gazetas (1984), Budhu and Davies (1988) mentioned that a constant profile represents a stiff homogenous clay layer, linear distribution of strength parameters represents a normally consolidated soft clay layer and a parabolic distribution represents for sandy soil. Hence, present study incorporates all three soil models as presented in Figure 2 irrespective of soil stiffness values considering a wide range of variability of such profile.

\subsubsection{Modelling of soil-raft system}

Piles are considered to be connected rigidly with raft foundation. A square raft is modelled using four noded plate elements discretised into square meshes. Each node of the plate is considered to have three degrees of freedom (two in mutually perpendicular horizontal directions and one in the vertical direction). Gazetas (1991) introduced equivalent springs that are located at the centroid of the foundation in each degree of freedom, to idealize the soil, which are given in Table 1. However, Dutta et al. (2009) showed that the idealisation of soil through distributed spring indicates a realistic representation of stress distribution over the raft area taking care of soil flexibility. Hence, raft-soil interaction is modelled using distributed linear springs connected below the entire raft area. Stiffness of distributed lateral springs in two mutually perpendicular horizontal directions (lateral $\left(K_{x 1}\right)$ and longitudinal $\left.\left(K_{x 2}\right)\right)$ are assigned following Dutta et al. (2009) as follows:

$$
\begin{aligned}
& K_{x 1}=K_{x G 1} / n^{2} ; \\
& K_{x 2}=K_{x G 1} / n^{2},
\end{aligned}
$$

where: $K_{x G 1}$ and $K_{x G 2}$ are the overall lateral stiffness of soil spring (Gazetas 1991) attached beneath the raft in lateral and longitudinal directions, respectively and $n$ is the number of mesh divisions in lateral as well longitudinal direction giving rise to $n^{2}$ elements in the raft. Vertical stiffness formulation suggested by Gazetas (1991) takes to $n^{2}$ elements in the raft. Vertical stiffness formulation suggested by Gazetas (1991) takes care for the coupled lateral-rocking mode of vibration. Hence, vertical spring stiffness $\left(K_{y}\right)$ values are compared with the values provided by Gazetas (1991) and are adapted in a distributed form as presented in literature (Dutta et al. 2009): 


$$
K_{y}=\frac{5.4}{\left(n^{2}+2\right)} \cdot \frac{G l_{R}}{(1-v)}
$$

where: $G$ is the shear modulus of soil; $l_{R}$ is the length of raft and $v$ is the Poisson's ratio of soil. The shear modulus of soil (in $\mathrm{t} / \mathrm{ft}^{2}$ ) is computed using the relationship given by Ohsaki and Iwasaki (1973) as presented below:

$$
G=120 N^{0.8}
$$

where $N$ is the SPT value of soil. Shear modulus of soil is calculated on the basis of reference $N$ value defined at a depth of one diameter of pile below ground level as suggested by Gazetas (1984), available in Table 3 for different stiffness values of soil. Such assumption is considered to be valid, since variation of stiffness of soil seems to be marginal at this depth for three different soil profiles. Note that, shear modulus values are considered to be altered for different soil consistency. Stiffness of all intermediate vertical springs connected to the raft are assumed to be the same while the corner and peripheral vertical spring stiffness, one-fourth or half of the stiffness of intermediate vertical springs depending on their influence area.

\subsubsection{Modelling of soil-pile system}

Pile-soil interaction phenomenon is modelled through beams on Winkler's foundation (BWF) technique where discrete soil springs in equivalent sense are attached at regular intervals of pile nodes. But in reality, soil is weak in tension and gap formation between pile and soil is a well admitted phenomenon which is not accounted in the discrete soil springs due to simplicity. Further, it is observed that gapping effect seems to be marginal in case of fixed head pile (Pender, Satwayan 1996). In fact, present study is mainly motivated to gaze at the effect of soil flexibility on dynamic characteristics and response of the system which might be taken care of by adopting such simplified pile-soil modelling, attributing only compression behaviour of soil. Stiffness values of such springs are derived from lateral subgrade modulus of soil medium. This technique has been extensively used in case of laterally loaded piles under static loading as reported in previous studies (e.g. Poulos, Davis 1980; Banerjee, Davies 1978; Randolph 1981; Hsiung 2003). In case of dynamic loading, beams on dynamic Winkler's foundation (BDWF) are used to model soil-pile interaction making a compromise between model complexity and accuracy in dynamic responses, instead of rigorous 3D FE model for single pile or pile group (e.g. Pender,

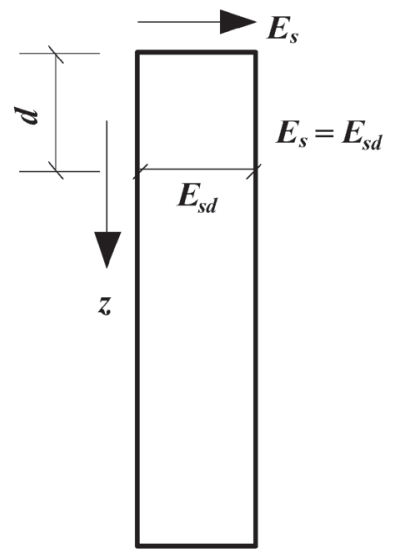

(a) Constant

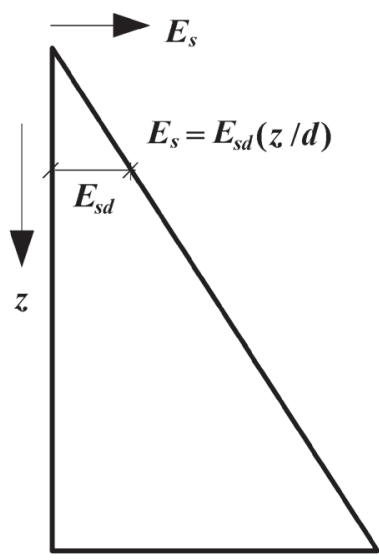

(b) Linear

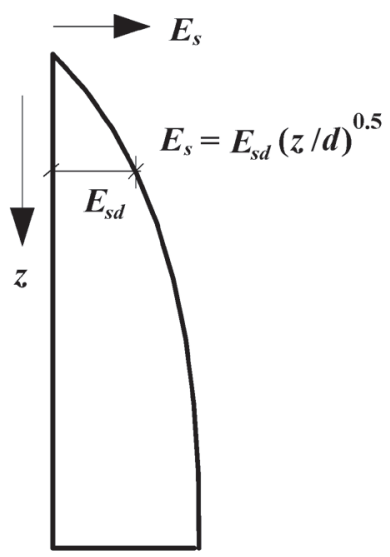

(c) Parabolic

Fig. 2. Three idealized soil profiles considered: a) constant, b) linear and c) parabolic (Gazetas 1984)

Table 1. Stiffness of equivalent springs along various degree of freedom (Gazetas 1991)

\begin{tabular}{ll}
\hline Degrees of freedom & Stiffness of equivalent soil spring \\
\hline Vertical $\left(K_{v}\right)$ & $\left(2 G L_{R} /(1-v)\right)\left(0.73+1.5 \chi^{0.75}\right)$ \\
\hline $\begin{array}{l}\text { Horizontal }\left(K_{x G 1}\right) \\
\text { (lateral direction) }\end{array}$ & $\left(2 G L_{R} /(2-v)\right)\left(2+2.54 \chi^{0.85}\right)$ \\
\hline $\begin{array}{l}\text { Horizontal }\left(K_{x G 2}\right) \\
\text { (longitudinal direction) }\end{array}$ & $\left(2 G L_{R}(1-v)\right)\left(0.73+1.54 \chi^{0.75}-\left(0.2(0.75-V) G L_{R}\left(1-\left(B / L_{R}\right)\right.\right.\right.$ \\
\hline
\end{tabular}

where: $\chi=A_{b} / 4 L_{R}^{2}, A_{b}$ is the area of the foundation considered; $B$ and $L_{R}$ are half width and halflength of a rectangular foundation, respectively; $G$ is shear modulus of soil and $v$ is the Poisson's ratio of soil. 
Satyawan 1996; Tajimi 1969; Gazetas, Dobry 1984; Badoni, Makris 1996; Makris, Gazetas 1992; Gazetas, Makris 1991; Novak 1974; Nikolaou et al. 2001; Boulengar et al. 1999; Curras et al. 2001). Distributed soil springs are considered as linear in some of these studies and while non-linear in some other, along with other physical interaction phenomenon between pile and soil. Stiffness of soil springs are considered as frequency dependent in some of the studies (e.g. Novak 1974; Badoni, Makris 1996). However, it has also been observed that frequency of input motion may not have a substantial effect. In fact, such stiffness remains constant throughout the predominant range of frequency content of an earthquake (Novak 1974; Makris, Gazetas 1992; Gazetas et al. 1993; NCHPR 461 2001). Hence, while studying the behaviour of entire system containing structure, raft, pile and soil, present study proceeds with a simpler idealization of pile-soil interaction with piles laterally supported by frequency independent soil springs. The stiffness of soil springs are calculated following well accepted literature (Reese, Matlock 1956; Gazetas, Dobry 1984; Bowles 1997) and assigned to individual distributed soil springs on the basis of tributary area of pile.

However, further justification of idealizing soil structure interaction modelling by beam on linear Winkler's foundation may be considered from well accepted literature proposed by Gazetas and his co-workers (e.g. Velez et al. 1983; Gazetas 1984; Makris, Gazetas 1992; Gazetas et al. 1993). The literature suggested by Gazetas and his co-workers mainly attempted to present the expression for dynamic stiffness of a single pile (Velez et al. 1983; Gazetas 1984) and for pile groups (Makris, Gazetas 1992; Gazetas et al. 1993) which have been verified by well accepted analytical, numerical and experimental studies (Blaney et al. 1976; Ohta et al. 1980; Randolph 1981; Kaynia, Kausel 1991). However, these stiffness values are mainly a function of static stiffness of a single pile, multiplied by frequency dependent dynamic coefficient and in case of group pile, dynamic interaction factor is further prescribed to be multiplied. On the other hand, Gazetas et al. (1993) states that the spring constants are derived solely through curve fitting, i.e. by matching pile head stiffness from the Winkler and 3D finite element formulations. Hence, the same spring constant for distributed Winkler's springs in present study is considered as proposed by Gazetas and his co-workers in their different authoritative literature (Gazetas, Dobry 1984; Gazetas, Makris 1991; Gazetas et al. 1993; Makris, Gazetas 1992). Pile group interaction is avoided as it has been indicated out in well-established literature (Gazetas et al. 1991) that such factor may be avoided until a fine tuning of such factors may be made. In fact, dynamic analysis of pile involves frequency dependent group interaction factor which seem to be an important issue in order to predict the dynamic characteristics and response of the system. This issue may be studied in detail as a further scope, particularly emphasizing a more realistic and accurate modelling for a soil-pile raft-superstructure system, attributing a large number of case studies. The same effect is attempted to be studied in a limited form in the present paper, comparing it with the present modelling technique. However, the objective of the present study is to identify the effect of structure-raft-pile-soil interaction in response to structural and foundation elements, identifying the physical reasons for the same, rather than contributing on sensitivity or accuracy of modelling. Thus, such reasonably accurate yet simplified pile-soil modelling is adopted particularly in view of such large number of case studies. Linear finite element approach (FEA) is used to obtain the responses. Figure 3 shows a detailed representation of the finite element model used herein.

Several empirical formulae for determination of lateral modulus of subgrade reaction were recommended in literature (e.g. Reese, Matlock 1956; Douglas, Davis 1964; Nogami, Novak 1980; Reese 1977; Gazetas, Dobry 1984; Bowles 1997). Among all these models, correlations suggested by Matlock and Reese (1960), Gazetas and Dobry (1984) and Bowles (1997) based on different loading mechanisms (static and cyclic pile head loading) are widely accepted because of their simplicity. Furthermore, theory of elasticity was also accounted for these propositions and no comparison between such relations is suggested. Hence, more realistic values may be obtained from them. A brief discussion of each of such formulae is presented in the following section.

\section{Bowles (1997) approach}

Bowles (1997) proposed an empirical relationship for modulus of subgrade values as given below:

$$
\begin{gathered}
k_{h}(z)=A_{s}+B_{s} z^{m} ; \\
A_{s}=C\left(c N_{c} S_{c}+0.5 \gamma N_{\gamma} S_{\gamma}\right) ; \\
B_{s}=C \gamma N_{q} S_{q},
\end{gathered}
$$

where: $k_{h}$ is the subgrade modulus of soil; $A_{s}$ is the constant for either horizontal and vertical members; $B_{S}$ is the coefficient for depth variation; $z$ is the depth of interest below ground; $m$ is the exponent to give best fit $k_{h}$; and $C$ is a calibration factor based on allowable bearing capacity. Other bearing capacity and shape factors may be attributed to standard bearing capacity equation by Terzaghi and Hansen approach (Bowles 1997). Three possible variations namely, uniform, linear and parabolic, may be incorporated by setting $m$ as 0,1 and 2, respectively.

\section{Matlock and Reese (1960) approach}

A general distribution of $k_{h}$ with depth has been introduced by Matlock and Reese (1960), as given below:

$$
k_{h}(z)=\eta_{h} z^{m} / d
$$

where: $\eta_{h}$ is the coefficient of subgrade reaction; $z$ is the depth below surface; $d$ is the pile diameter and $m$ is an empirical index equal to or greater than zero. Typical val- 
ues of $\eta_{h}$ are given in Reese and Matlock (1956) for various types of soil. Three different types of soil profiles are incorporated changing empirical index values.

\section{Gazetas and Dobry (1984) approach}

Roesset and Angelides (1980) provided a relationship between subgrade modulus and soil Young's modulus, $E_{s}(z)$ as per theory of elasticity as given by:

$$
k_{h}(z)=\delta E_{s}(z)
$$

where $\delta$ is a constant. Typical values of $\delta$ for various soils and piles vary from 1.0-1.2 for fixed-head pile (Gazetas, Dobry 1984). However, a fixed value of $\delta=1.2$ recommended by Mylonakis and Gazetas (2002), Gazetas et al. (1993) and Markis and Gazetas (1992) for fixed head pile and the same value is adopted herein. The above three approaches need various parameters to estimate $k_{h}(z)$ which are listed in Table 2.

Estimated values of $k_{h}(z)$ for various soil stiffness values are also presented in the same table.
Vertical springs are also introduced at pile nodes to account for frictional shaft resistance ( $t-z$ spring) and tip resistance ( $q-z$ spring) respectively.

The input parameter of which are calculated as follows (Bowles 1997):

$$
\begin{gathered}
k_{t z}=\alpha s_{u} d ; \\
k_{q z}=360 s_{u} A_{b},
\end{gathered}
$$

where: $s_{u}$ is the undrained shear strength of soil at pile tip; $\alpha$ is the adhesion factor; $d$ is diameter of pile; and $A_{b}$ is the area of pile base section.

\subsection{Damping}

Previous studies (Satake et al. 2003) suggest that normal range of damping of building system vary within $2-8 \%$. Guidelines for estimating damping of soil medium have been prescribed in literature (e.g. Veletsos 1977; Gazetas 1991). However, this may go up to as high as $20 \%$ for

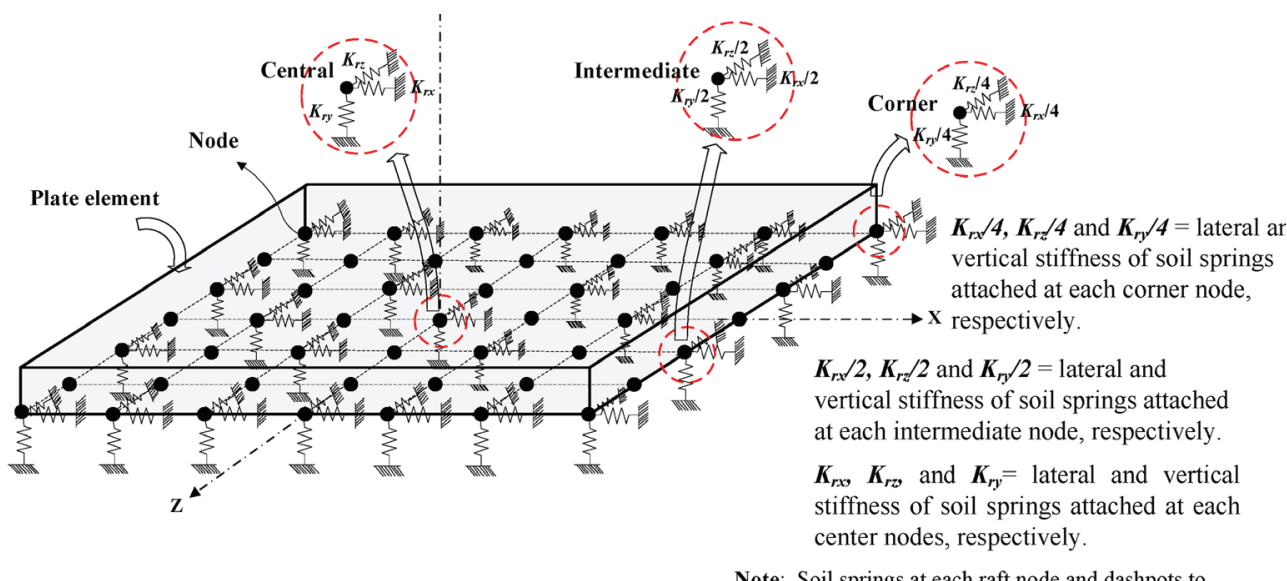

Note: Soil springs at each raft node and dashpots to represent soil damping are not shown to maintain clarity.

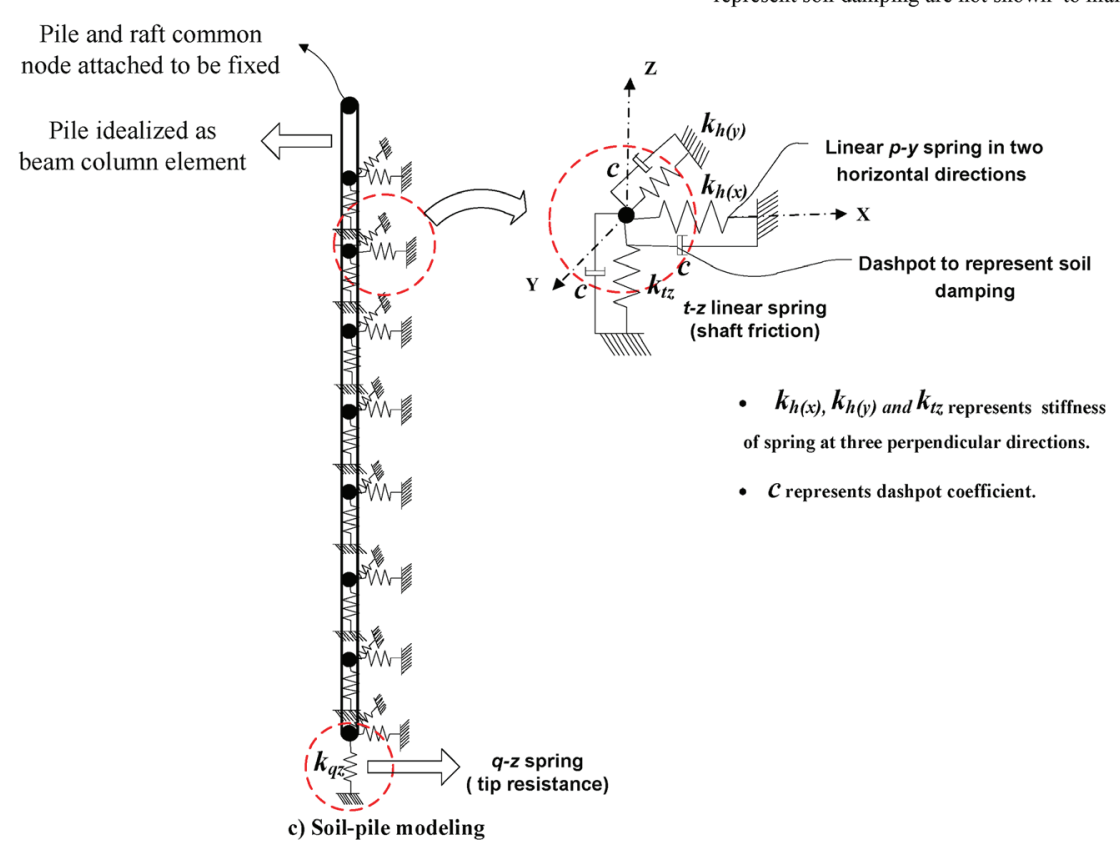

Fig. 3. Detailed representation of finite element model for (a) soil-raft and (b) soil-pile system 
Table 2. List of various parameters to determine values of subgrade modulus

\begin{tabular}{|c|c|c|c|c|c|c|}
\hline \multirow{2}{*}{ Stiffness of soil } & \multirow{2}{*}{$\begin{array}{c}\text { Method for } \\
\text { estimating } k_{x}(z)\end{array}$} & \multirow{2}{*}{ Parameters } & \multirow{2}{*}{ Values } & \multicolumn{3}{|c|}{$k_{h}(z)\left(\mathrm{kN} / \mathrm{m}^{2} / \mathrm{m}\right)$} \\
\hline & & & & Constant & Linear & Parabolic \\
\hline \multirow{10}{*}{$\begin{array}{l}\text { Very soft } \\
\left(s_{u}=9.8 \mathrm{kN} / \mathrm{m}^{2},\right. \\
\left.\gamma=13.5 \mathrm{kN} / \mathrm{m}^{3}\right)\end{array}$} & \multirow{7}{*}{ Bowles (1997) } & $N_{c}$ & 5.14 & \multirow{7}{*}{5784} & \multirow{7}{*}{$\begin{array}{c}5435+349 \\
(z / d)\end{array}$} & \multirow{7}{*}{$\begin{array}{l}5435+349 \\
(z / d)^{0.5}\end{array}$} \\
\hline & & $S_{c}$ & 1.3 & & & \\
\hline & & $N_{g}$ & 0 & & & \\
\hline & & $S_{g}$ & 0.6 & & & \\
\hline & & $\overrightarrow{N_{q}}$ & 1.0 & & & \\
\hline & & $S_{q}$ & 1.2 & & & \\
\hline & & $C$ & 83 & & & \\
\hline & $\begin{array}{l}\text { Matlock and } \\
\text { Reese (1960) }\end{array}$ & $\eta_{h}$ & $163 \mathrm{kN} / \mathrm{m}^{3}$ & 2727 & $\begin{array}{l}(163 / d) \\
(1+z)\end{array}$ & $\begin{array}{c}(163 / d) \\
\left(1+z+z^{0.5}\right)\end{array}$ \\
\hline & \multirow{2}{*}{$\begin{array}{l}\text { Gazetas and } \\
\text { Dobry (1984) }\end{array}$} & $\delta$ & 1.2 & \multirow{2}{*}{6000} & \multirow{2}{*}{$6000(z / d)$} & \multirow{2}{*}{$6000(z / d)^{0.5}$} \\
\hline & & $E s(z)$ & $5 \mathrm{MPa}$ & & & \\
\hline \multirow{10}{*}{$\begin{array}{l}\text { Soft } \\
\left(s_{u}=18.5 \mathrm{kN} / \mathrm{m}^{2},\right. \\
\left.\gamma=17.0 \mathrm{kN} / \mathrm{m}^{3}\right)\end{array}$} & \multirow{7}{*}{ Bowles (1997) } & $N_{c}$ & 5.14 & \multirow{7}{*}{10957} & \multirow{7}{*}{$\begin{array}{l}10260+ \\
697(z / d)\end{array}$} & \multirow{7}{*}{$\begin{array}{c}10260+697 \\
(z / d)^{0.5}\end{array}$} \\
\hline & & $S_{c}$ & 1.3 & & & \\
\hline & & $N_{g}$ & 0 & & & \\
\hline & & $S_{g}$ & 0.6 & & & \\
\hline & & $N_{q}$ & 1.0 & & & \\
\hline & & $S_{q}$ & 1.3 & & & \\
\hline & & $C$ & 83 & & & \\
\hline & $\begin{array}{l}\text { Matlock and } \\
\text { Reese (1960) }\end{array}$ & $\eta_{h}$ & $543 \mathrm{kN} / \mathrm{m}^{3}$ & 7723 & $\begin{array}{l}(543 / d) \\
(1+z)\end{array}$ & $\begin{array}{c}(543 / d) \\
\left(1+z+z^{0.5}\right)\end{array}$ \\
\hline & \multirow{2}{*}{$\begin{array}{l}\text { Gazetas and } \\
\text { Dobry (1984) }\end{array}$} & $\delta$ & 1.2 & \multirow{2}{*}{12000} & \multirow{2}{*}{$12000(z / d)$} & \multirow{2}{*}{$12000(z / d)^{0.5}$} \\
\hline & & $E s(z)$ & $10 \mathrm{MPa}$ & & & \\
\hline \multirow{10}{*}{$\begin{array}{l}\text { Moderately stiff } \\
\left(s_{u}=36.8 \mathrm{kN} / \mathrm{m}^{2},\right. \\
\left.\gamma=18.5 \mathrm{kN} / \mathrm{m}^{3}\right)\end{array}$} & \multirow{7}{*}{ Bowles (1997) } & $N_{c}$ & 5.14 & \multirow{7}{*}{21256} & \multirow{7}{*}{$\begin{array}{l}20409+ \\
847(z / d)\end{array}$} & \multirow{7}{*}{$\begin{array}{c}20409+847 \\
(z / d)^{0.5}\end{array}$} \\
\hline & & $S_{c}$ & 1.3 & & & \\
\hline & & $N_{g}$ & 0 & & & \\
\hline & & $S_{g}$ & 0.6 & & & \\
\hline & & $N_{q}$ & 1.0 & & & \\
\hline & & $S_{q}$ & 1.3 & & & \\
\hline & & $C$ & 83 & & & \\
\hline & $\begin{array}{l}\text { Matlock and } \\
\text { Reese (1960) }\end{array}$ & $\eta_{h}$ & $1085 \mathrm{kN} / \mathrm{m}^{3}$ & 25607 & $\begin{array}{c}(1085 / d) \\
(1+z)\end{array}$ & $\begin{array}{c}(1085 / d) \\
\left(1+z+z^{0.5}\right)\end{array}$ \\
\hline & \multirow{2}{*}{$\begin{array}{l}\text { Gazetas and } \\
\text { Dobry (1984) }\end{array}$} & $\delta$ & 1.2 & \multirow{2}{*}{36000} & $36000(z / d)$ & $36000(z / d)^{0.5}$ \\
\hline & & $E s(z)$ & $30 \mathrm{MPa}$ & & $50000(21 a)$ & $30000(2 / a)$ \\
\hline
\end{tabular}

the subgrade medium. In fact, it has been suggested that consideration of $5 \%$ material damping of soil could be a realistic assumption for understanding the behaviour of pile-raft system (Velez et al. 1983). Such effect of damping (with material and radiation) due to interaction between foundation and soil on overall response of soil-foundation-structure system is rigorously investigated by Roy and Dutta (2010) with various feasible choices of damping ratio of soil, for instance within a range of $2 \%$ to $30 \%$ of critical damping. The objective of this previous study was to see the effect of soil damping which comprises of both material as well as radiation damping part on calculating overall flexible base damping parameter and most effectively on the response of the whole system. However, such study was limited to shallow footings only. It was found that consideration of high damping for soil (including material and radiation), even up to the extent of $30 \%$ of critical damping, will make a marginal difference in response of the elements of system as compared to what is obtained with $5 \%$ of critical damping of soil. Finally, they reported that consideration of $5 \%$ of critical damping in each mode of combined structure-foundation and soil system is a reasonable input which marginally overestimates the response of system. Furthermore, many seismic codes (e.g. Indian seismic design guideline, BIS 1893-Part-I 2002) also suggest that $5 \%$ of critical damping is reasonable for concrete structures. Therefore, to strike a balance between rigour and accuracy, $5 \%$ of critical damping in each mode of vibration of pile-raft-soil and superstruc- 
ture system is considered for the present study regardless of structural support condition. Based on similarity of the issue of soil damping with previous study by Roy and Dutta (2010), the same foundation damping is considered to be applicable in present study for pile-supported structure. Such a consideration of $5 \%$ of critical damping for pile-soil foundation system primarily indicates material or hysteretic damping part of soil, while radiation counterpart is appreciably marginal. However, it has been observed that material damping of pile-soil system is a frequency independent constant parameter which acts in the range of lower frequency up to a maximum value of fundamental natural frequency of soil deposit (Gazetas, Dobry 1984). The input motion used in this study contains very high amplitudes at lower frequency range implicating maximum response of structures and hence material damping will rather be more appropriate for predicting the response of the whole system. However, it would be interesting to study the influence of frequency dependent damping on pile-soil foundation system in detail, through a further rigorous modelling, by introducing separated lateral dashpots at each node of pile elements, yielding the cases where such influence can be considerable, and also the extent of such influence. This may be treated as an important further scope of the present study as the major objective of this paper is limited to provide a prima facei input on the effect of SSI in case of pile supported structures.

\subsection{Ground motion}

An artificially generated earthquake acceleration history consistent with BIS 1893 (1984) specified design spectrum, having PGA (peak ground acceleration) of $0.1 \mathrm{~g}$ is chosen from the previous studies (Dutta et al. 2004; Dutta, Das 2002) as input ground motion in the present analysis. The generated acceleration time history and the design response spectrum are shown in Figure 4. Design spectrum of BIS 1893 (1984) superimposed on the response spectrum of this ground motion indicates the consistency of these motion with this design spectrum. So, this earthquake ground motion is expected to have similar frequency content as expected through well accepted design spectrum. Hence, response obtained from such a ground motion is expected to produce trend indicating results.

\section{Case studies}

Present study attempts to examine the effect of soilstructure interaction on piled raft-structure under seismic excitation for different fundamental periods of structure, soil stiffness values and pile length to diameter ratios. Four representative natural periods of vibration, namely, $0.25 \mathrm{sec}, 0.5 \mathrm{sec}, 1 \mathrm{sec}$, and $2 \mathrm{sec}$ are taken into account for the short, medium and long period structure, respectively. Realistically, $0.25 \mathrm{sec}, 0.5 \mathrm{sec}, 1 \mathrm{sec}$, and $2 \mathrm{sec}$. fundamental periods may be exhibited by the structures with three-storeyed, five-storeyed, ten-storeyed and twenty-storeyed buildings, respectively. The behaviour of these multi-degrees of freedom systems are attempted to be studied through equivalent SDOF system having same lateral period by adjusting mass and stiffness. Three different types of soil stiffness values, namely, very soft, soft and moderately stiff are considered to represent relative stiffness values of pile to soil $\left(E_{p} / E_{s d}\right)$ in the order of 5000, 2500 and 800 , respectively representing incompressible to compressible behaviour of pile based on as-
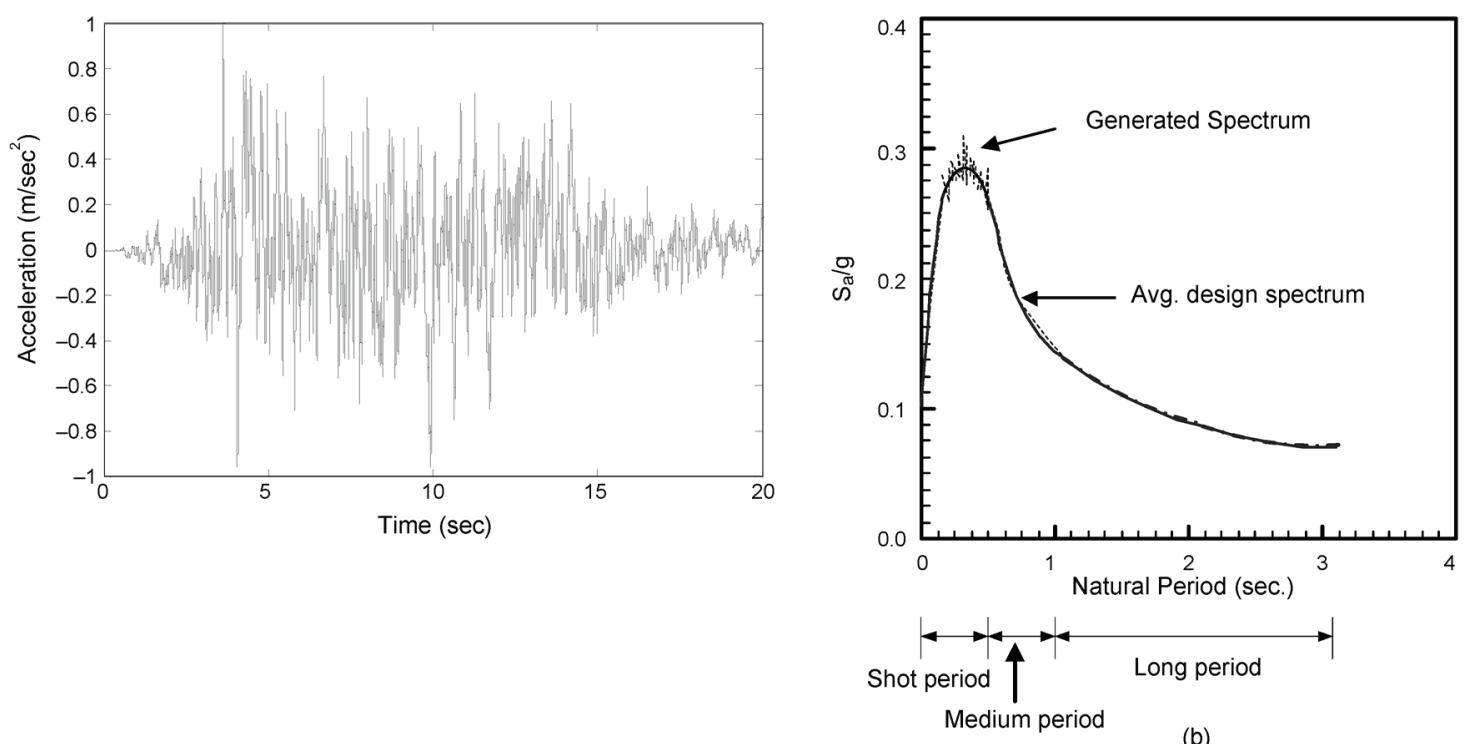

(b)

Fig. 4. Synthetic ground motion used in the present study, chosen from literature (Dutta et al. 2004; Dutta, Das 2002): a) acceleration time history; and b) spectrum of simulated ground motion superposed on design spectrum of IS: 1893 (1984) corresponding to $2 \%$ damping 
Table 3. Typical Soil parameters considered for study as used in Bhattacharya et al. (2004)

\begin{tabular}{lccc}
\hline Stiffness of clay & Very soft & Soft & $\begin{array}{c}\text { Moderately } \\
\text { stiff }\end{array}$ \\
\hline $\mathrm{N}$ value & 1 & 3 & 6 \\
\hline$s_{u}\left(\mathrm{kN} / \mathrm{m}^{2}\right)$ & 9.80 & 18.50 & 36.80 \\
\hline$\gamma_{\text {sat }}\left(\mathrm{kN} / \mathrm{m}^{3}\right)$ & 13.50 & 17.0 & 18.50 \\
\hline $\begin{array}{l}\text { Compression index, } \\
C_{c}\end{array}$ & 0.279 & 0.189 & 0.135 \\
\hline $\begin{array}{l}\text { Void ratio } \\
\left(e_{0}\right)\end{array}$ & 1.20 & 0.90 & 0.72 \\
\hline $\begin{array}{l}\text { Young's modulus, } \\
E_{s d}(\mathrm{MPa}) \text { (Bowles } \\
1997)\end{array}$ & 5.0 & 10.0 & 30.0 \\
\hline
\end{tabular}

sumed Young's modulus of pile $\left(E_{p}\right)$ of $25 \times 10^{6} \mathrm{kN} / \mathrm{m}^{2}$. Characteristic Young's modulus of soil $\left(E_{s d}\right)$ is used to define relative stiffness of pile in various consistencies of soil. Typical parameters considered for these soil types are presented in Table 3. Equivalent spring stiffness values are calculated for different soil types corresponding to all possible combinations of approaches for evaluating lateral subgrade modulus along with three typical depth wise variations of the same. The Poisson's ratio (v) of soil is considered to be equal to 0.5 for all types of clay (IS: 5249 1992).

A piled raft having plan area of $10 \times 10 \mathrm{~m}$ is taken into consideration and a plan area of $8.5 \times 8.5 \mathrm{~m}$ is retained for superstructure floor on the boundary of which peripheral columns are placed. Based on a convergence study, raft is discretised into 1600 numbers (i.e. $n=40$ ) and piles are divided into 18, 22 and 30 elements for $L / d=60,75$ and 100 , respectively. The convergence study is performed through observing the change in normalised shear at column and pile. Such normalised response is presented as a function of number of mesh divisions in raft. Normalised shear indicates the ratio of shear force obtained from SSI model to fixed base condition. When pile is being modelled as beam column elements, for which stiffness is developed on the basis of actual shape function, no further discretisation is needed to improve the accuracy. Results of convergence study are presented for sample case of lumped mass stick model, supported by a raft foundation attached with a single pile as shown in Figure 5. Graphs presented in Figure 5 clearly show that there is a little influence of increase in mesh divisions beyond 1000. Gravity load is considered to be $8.0 \mathrm{kN} / \mathrm{m}^{2}$ per floor with a realistic consideration of live load for design of foundation. Floating pile group is designed based on imposed superstructure load and subsoil condition. Allowable bearing capacity of the soil is estimated based on general shear failure and permissible settlement criteria. It is assumed that a part of the superstructure weight is taken by the raft, based on the allowable bearing capacity of the soil it is resting on.

The remaining weight is considered to be carried by piles. Raft foundation is assumed to be supported by a group of piles. Three different pile length-to-diameter ratios $(L / d), 60,75$ and 100 are selected. Pile spacing $(S)$-to-diameter $(d)$ ratio $(S / d)$ is kept constant at 3 and thickness of the raft is varied with different natural period of structure. A detailed scheme for all case studies is summarised in Table 4. To arrive at only realistic cases, it has been found that raft-pile foundation is a feasible footing system for very soft soil, while such a foundation system may become uneconomic for structures on soft to moderately stiff soil, if they have less number of storeys having less fundamental natural period. Only structures with larger number of storeys, with larger fundamental period may have raft-pile foundation feasible. Such cases are only included in the scope of the study to have realistic inferences. From this viewpoint, the entire period ranges are not covered for soft and medium soil cases. However, superstructure with fundamental period $\left(T_{\text {fixed }}\right)$ of $0.25 \mathrm{sec}$ embedded in very soft soil is found to be an exceptional case, for which piled raft foundation is a too conservative solution.
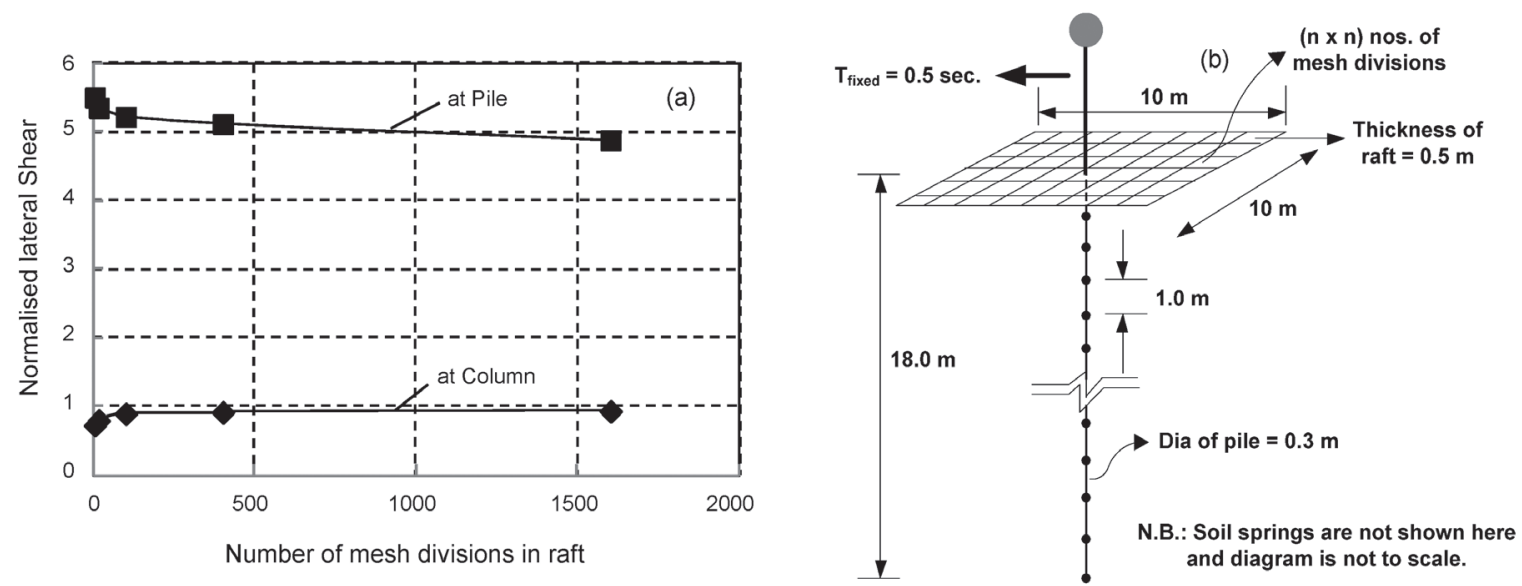

Fig. 5. Representation of mesh sensitivity results: a) normalised shear at column and pile for various choice of mesh divisions in raft; b) schematic diagram of soil-piled raft-structure system used in convergence study 
Table 4. Summary of case studies

\begin{tabular}{|c|c|c|c|c|c|c|c|c|c|}
\hline $\begin{array}{l}\text { Time period } \\
\text { of structure } \\
T_{\text {fixed }}(\mathrm{sec})\end{array}$ & $\begin{array}{l}\text { Soil stiffness } \\
\text { (in terms of } \\
\text { relative stiffness } \\
\text { of pile) }\end{array}$ & Soil profile & $\begin{array}{l}\text { Raft } \\
\text { thickness } \\
(\mathrm{mm})\end{array}$ & $\begin{array}{l}\text { Pile group } \\
\text { configuration }\end{array}$ & $\begin{array}{c}L \\
(\mathrm{~m})\end{array}$ & $\begin{array}{c}d \\
(\mathrm{~m})\end{array}$ & $S / d$ & $L / d$ & $\begin{array}{l}\text { Method } \\
\text { adopted } \\
\text { for } k_{x}(z)\end{array}$ \\
\hline \multirow{3}{*}{0.25} & $\begin{array}{c}\text { Very soft } \\
\left(E_{p} / E_{s d}=5000\right)\end{array}$ & \multirow{3}{*}{$\begin{array}{l}\text { Constant, } \\
\text { Linear, } \\
\text { Parabolic }\end{array}$} & NPR & NPR & - & - & \multirow{12}{*}{$\stackrel{\circ}{\dot{m}}$} & \multirow{12}{*}{8} & \multirow{12}{*}{ 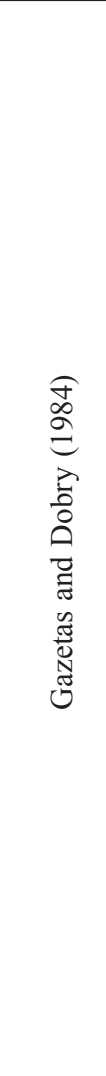 } \\
\hline & $\begin{array}{c}\text { Soft } \\
\left(E_{p} / E_{s d}=2500\right)\end{array}$ & & NPR & NPR & - & - & & & \\
\hline & $\begin{array}{l}\text { Moderately stiff } \\
\left(E_{p} / E_{s d}=800\right)\end{array}$ & & NPR & NPR & - & - & & & \\
\hline \multirow{3}{*}{0.5} & $\begin{array}{c}\text { Very soft } \\
\left(E_{p} / E_{s d}=5000\right)\end{array}$ & \multirow{3}{*}{$\begin{array}{l}\text { Constant, } \\
\text { Linear, } \\
\text { Parabolic }\end{array}$} & 750 & $(4 \times 4),(3 \times 3),(2 \times 3)$ & $18,22.5,30$ & 0.30 & & & \\
\hline & $\begin{array}{c}\text { Soft } \\
\left(E_{p} / E_{s d}=2500\right)\end{array}$ & & NPR & NPR & - & - & & & \\
\hline & $\begin{array}{l}\text { Moderately stiff } \\
\left(E_{p} / E_{s d}=800\right)\end{array}$ & & NPR & NPR & - & - & & & \\
\hline \multirow{3}{*}{1.0} & $\begin{array}{c}\text { Very soft } \\
\left(E_{p} / E_{s d}=5000\right)\end{array}$ & \multirow{3}{*}{$\begin{array}{l}\text { Constant, } \\
\text { Linear, } \\
\text { Parabolic }\end{array}$} & 1000 & $(6 \times 6),(5 \times 5),(5 \times 5)$ & $18,22.5,30$ & 0.30 & & & \\
\hline & $\begin{array}{c}\text { Soft } \\
\left(E_{p} / E_{s d}=2500\right)\end{array}$ & & 1000 & $(2 \times 3),(3 \times 3),(2 \times 2)$ & $18,22.5,30$ & 0.30 & & & \\
\hline & $\begin{array}{l}\text { Moderately stiff } \\
\left(E_{p} / E_{s d}=800\right)\end{array}$ & & NPR & NPR & - & - & & & \\
\hline \multirow{3}{*}{2.0} & $\begin{array}{c}\text { Very soft } \\
\left(E_{p} / E_{s d}=5000\right)\end{array}$ & \multirow{3}{*}{$\begin{array}{l}\text { Constant, } \\
\text { Linear, } \\
\text { Parabolic }\end{array}$} & 1500 & $(9 \times 9),(8 \times 8),(7 \times 7)$ & $18,22.5,30$ & 0.30 & & & \\
\hline & $\begin{array}{c}\text { Soft } \\
\left(E_{p} / E_{s d}=2500\right)\end{array}$ & & 1500 & $(6 \times 6),(5 \times 5),(5 \times 5)$ & $18,22.5,30$ & 0.30 & & & \\
\hline & $\begin{array}{l}\text { Moderately stiff } \\
\left(E_{p} / E_{s d}=800\right)\end{array}$ & & 1500 & $(3 \times 4),(3 \times 3),(3 \times 3)$ & $18,22.5,30$ & 0.30 & & & \\
\hline
\end{tabular}

For all cases: $P G A=0.1 \mathrm{~g}$, Damping $=5 \%, \mathrm{NPR}=$ No piles are required, $4 \times 4$ indicates 4 rows $\times 4$ columns, order of $(4 \times 4)$, $(3 \times 3),(2 \times 3)$ indicates pile group of length $18 \mathrm{~m}, 22.5 \mathrm{~m}$ and $30 \mathrm{~m}$ respectively.

This is due to the fact that a structure with $T_{\text {fixed }}=$ $0.25 \mathrm{sec}$ resembles a three storeyed building frame which can also be considered as an equivalent SDOF system having $8.5 \times 8.5 \mathrm{~m}$ (thickness $=1.0 \mathrm{~m}$ ) roof slab supported with four $300 \times 300 \mathrm{~mm}$ square columns. Considering the superstructure weight of such structure a shallow foundation (raft) is found to be safe in case of very soft soil. Hence, addition of piles seems to be an irrational design and thereby not included in the analysis. However, a 4-storeyed building (fundamental period is assumed to be $0.5 \mathrm{sec}$ in fixed base condition) typically representative of moderately stiff period of a structure supported by a $3 \times 3$ floating pile group of $L / d=60$ embedded in very soft soil having constant variation of $E_{s}$ with depth is considered. In this case, thickness of raft is rationally assumed to be $500 \mathrm{~mm}$. Since, Table 4 only presents the cases to be studied based on SDOF modelling, this present MDOF system is not included in the table.

\section{Results and discussion}

\subsection{Validation of model used in numerical study}

An attempt has been made to validate the proposed numerical model by comparing lateral natural period of the system obtained from present SSI model and different well accepted analytical solutions available in literature (e.g. Rovithis et al. 2009). The classical analytical expressions for calculating natural time period of structure incorporating SSI are presented in Table 5. Table 6 represents lateral natural period of structure incorporating SSI evaluated by using above mentioned analytical expressions as well as present modelling for a few exemplary cases of soil-pile raft-structure models which are also included among the cases presented herein. In the above analytical expressions, pile-group foundation stiffness depending on frequency dependent interaction factors under various degrees of freedom, i.e. $K_{x x}$ (sway), $K_{r r}$ (rocking), $K_{x r}$ (coupled sway-rocking) are evaluated using empirical and analytical solutions following literature proposed by Gazetas (1984), Dobry, Gazetas (1988) and Makris and Gazetas (1992). Frequency dependent 
group interaction factor under sway motion for computing pile- group lateral stiffness is considered in all these expressions. Though the present modelling does not incorporate any effect of group interaction, but to visualize the effect of frequency dependent group interaction factor in pile-group stiffness under sway motion, three different dimensionless frequencies $\left(a_{0}=\omega d / V_{s}\right.$, where $\omega=$ angular frequency of harmonic motion and $d$ is the pile diameter, $V_{s}=$ shear wave velocity in soil layer) of $0.05,0.3$ and 1.0 are selected for computation of $T_{s s i}$ from analytical formulation. Another case without considering group interaction factor has also been computed and presented for the sake of comparison. In case of Eqn (10) proposed by Maravas et al. (2007), the damping ratio for different conditions is considered uniform as 0.05 for the sake of simplicity. Further, it is worth mentioning that damping ratio under translation motion is generally higher than rocking for pile foundation (Gazetas et al. 1993). To verify such observation, different combinations of realistic damping ratios under translational and rocking motion, such as, $(5 \%$ and $2 \%),(8 \%$ and $5 \%),(10 \%$ and $5 \%$ ), respectively are considered along with damping ratio of other modes unchanged to $5 \%$ for calculation of natural period of system. No change is observed in the results as compared to the uniform 5\% damping for all modes. In fact, any system has very less influence on its natural frequency or period due to change in damping while following from expression of damped frequency of systems available in standard literature (Chopra 2008; Clough, Penzien 1995).
The natural lateral period considering for these different formulations are computed and compared with the values obtained using a simple soil-pile-raft-structure model, and presented in Table 6. This table shows that the present model predicts the period of soil-pile-raftstructure system with reasonable accuracy and may be used for obtaining valuable insight into the seismic behaviour of such structural systems. However, it is observed from Table 6 that the effect of coupled stiffness for pile group seems to be marginal on natural period of vibration for the particular piled raft-superstructure systems under investigation. While, the effect of such stiffness is considered to be an important parameter in soilpile-structure system (Rovithis et al. 2009). Among the abovementioned analytical expressions, Gazetas (1996) has proposed the contribution of coupled stiffness as indicated in Eqn (10). It is evident from the Eqn (10) that the natural period of the system depends upon the ratio of $k_{s t r} / K_{x x}$ (ratio of structural stiffness to sway-rocking stiffness of foundation) and $k_{s t r} / K_{r r}$ (ratio of structural stiffness to rocking stiffness of foundation). It is observed that incorporation of sway-rocking stiffness and rocking stiffness exhibit marginal increase in fundamental period of soil-pile raft-structure system. Furthermore, extent of such increase in natural period is observed to be within $10 \%$ compared to other two relations proposed by Veletsos and Meek (1974) and Maravas et al. (2007). The effect of cross-sway stiffness seems to be marginal for the considered benchmark cases. This is essentially due to the fact that the long period structures supported by a flexible

Table 5. Classical expressions for calculating natural time period of structure incorporating SSI (Rovithis et al. 2009)

Sl. No. $\begin{gathered}\text { Relation proposed } \\ \text { by }\end{gathered}$

Analytical expressions

$$
T_{s s i}=T_{f i x e d} \sqrt{1+\frac{k_{s t r}}{K_{x x}}\left(1+\frac{K_{x x} H_{s t r}^{2}}{K_{r r}}\right)}
$$

1- Veletsos and Meek (1974)

where: $T_{s s i}, T_{f i x e d}, k_{s t r}$, and $H_{s t r}$ denotes the natural period considering SSI, natural period under fixed base condition, stiffness of structure and height of structure respectively; $K_{x x}$ and $K_{r r}$ denote stiffness of foundation under swaying and rocking motion respectively. The above equation was developed for structures supported on rigid mat foundation, but it is often utilized for variety of foundations and also incorporated in seismic codes (ATC-3 1978; FEMA 440 2005).

2 Gazetas (1996)

$$
T_{s s i}=T_{f i x e d} \sqrt{1+\frac{k_{s t r}}{K_{x x}}+\frac{k_{s t r} H_{s t r}}{K_{x r}}+\frac{k_{s t r} H_{s t r}^{2}}{K_{r r}}} .
$$

where $K_{x r}$ denotes coupled sway-rocking stiffness of foundation and other notations are same as introduced in Eqn (9).

Maravas et al. (2007)

$$
T_{s s i}=T_{\text {fixed }} \sqrt{\frac{k_{s t r}}{K_{x x}}\left(\frac{1+4 \bar{\zeta}^{2}}{1+4 \bar{\zeta}_{x}^{2}}\right)+\frac{k_{s t r} H_{s t r}^{2}}{K_{r r}}\left(\frac{1+4 \bar{\zeta}^{2}}{1+4 \bar{\zeta}_{\theta}^{2}}\right)+\left(\frac{1+4 \bar{\zeta}^{2}}{1+4 \zeta_{s t r}^{2}}\right)}
$$

where $\zeta_{s t r}, \bar{\zeta}, \bar{\zeta}_{x}$ and $\bar{\zeta}_{\theta}$ represent the damping ratio of structure under fixed base, flexibly supported structure, swaying of foundation and rocking of foundation respectively and remaining other notations are same as introduced in Eqn (9). 
piled raft system in different soils may experience marginal effect of soil structure interaction. The reason may be further explained by a flexible spring being connected in series with another flexible spring, exhibiting less change while combined as compared to what is exhibited by a stiff spring being connected with a flexible spring. Such effect might be significant for short period structure supported by flexible piled raft system or rigid piled raft system which is beyond the scope of the study.

\subsection{Effects of SSI on fundamental period of the system $\left(\boldsymbol{T}_{s s i}\right)$}

The fundamental lateral periods of vibration of pile raftstructure system accounting SSI $\left(T_{s s i}\right)$ are obtained and compared to the natural periods of the structures under fixed base conditions $\left(T_{\text {fixed }}\right)$. The comparison presented in Table 7 illustrates the effect of soil and pile parameters on $T_{s s i}$. Note that, Table 7 reported only those cases where pile foundation is a feasible option. It is observed that the period of soil-pile raft-structure system lengthens with respect to the natural period of vibration under fixed base conditions in all cases due to SSI effect. Results show that increasing pile length leads to considerable lengthening of $T_{s s i}$. This implies that the effect of SSI is significant for slender piles. For example, a structure having $T_{\text {fixed }}=0.5 \mathrm{sec}$ exhibits an increase of the same to $1.22 \mathrm{sec}$ for a $L / d$ ratio of 100 if it is embedded in soft soil with constant lateral subgrade modulus with depth. However, the lengthened period is observed as low as $0.79 \mathrm{sec}$ for $L / d$ ratio of 60 . Further, a 4 -storeyed building represented as a MDOF system implying a $T_{\text {fixed }}=$ $0.5 \mathrm{sec}$ shows a lengthened period of $0.70 \mathrm{sec}$ which confirms the validity of observations achieved through SDOF idealization. The table also shows that stiff structures may have considerable lengthening of period due to SSI. Similar observations have also been made by Rovithis et al. (2009). Based on the results, it is also observed that soil consistency may have significant effect on $T_{s s i}$. Interestingly, period lengthening of soil-pile raft-structure system seems to be more in case of moderately stiff soil as compared to the soft soil. For a structure founded on moderately stiff soil requires fewer piles compared to the structures founded on soft soil for the same superstructure load. Thus, the structure on soft soil has more stiffness contributed by larger number of piles in its raftpile-soil system. This result in lesser overall stiffness of soil-pile system in medium soil, leading to a larger lengthening of natural period of vibration as compared to its counterpart in soft soil, though this observation appears to be apparently counter intuitive. Present study exhibits a lengthening of period to the extent of about $2 \%$ to $140 \%$ due to soil consistency ranging from very soft to moderately stiff.

\subsection{Effects of SSI on seismic base shear}

Seismic base shear gives a broad idea about the seismic lateral vulnerability in the elastic range of response which is considered as one of the fundamental inputs for seismic design. Hence, the variations in the base shear for piled-raft supported superstructure due to the effect of soil-structure interaction is investigated. It is observed that the overall stiffness of the pile raft-structure system changes considerably due to inclusion of soil flexibility which results in appreciable change in the base shear. Present study deals with several soil and pile parameters. Shear force transmitted in ground storey columns $\left(V_{B(c o l)}\right)$ and to pile heads $\left(V_{B(p i l e)}\right)$ is obtained for soilpile raft-structure system considering the range of parameters described earlier. Since total shear transmitted to the soil is distributed through the total length of pile, the maximum shear $\left(V_{B(p i l e)}\right)$ in pile occurs at their head level. These base shear forces are normalised with respect to the base shear $\left(V_{B(\text { fixed })}\right)$ obtained under fixed base condition. Normalised base shear forces at ground storey columns and pile head $\left(V_{B(c o l)} / V_{B(\text { fixed })}\right.$ and $V_{B(\text { pile })} /$ $\left.V_{B(\text { fixed })}\right)$, respectively are plotted as a function of period of structures under fixed base condition. The normalised values greater than one indicates an increased response as compared to what is obtained considering a fixed base condition and vice versa indicates decreased response. Effect of three different approaches to estimate soil subgrade modulus, $k_{h}(z)$, on the responses of pile raft-structure system is examined for all three different soil consistency values and three depth wise variations of $E_{S}(z)$. Figures 6(a) and 6(b) present $V_{B(\text { col })} / V_{B(\text { fixed })}$ and $V_{B(\text { pile })} / V_{B(\text { fixed })}$ respectively as a function of lateral periods of structure at fixed base condition, for $k_{h}(z)$ values computed considering the three different approaches (i.e. Bowles 1997; Matlock, Reese 1960; Gazetas, Dobry 1984) for constant variation of $E_{s}(z)$. Marginal difference in normalised transmitted shear forces to column and pile head $\left(V_{B(\text { col })} / V_{B(\text { fixed })}\right.$ and $\left.V_{B(\text { pile })} / V_{B(\text { fixed })}\right)$ is observed for the three different approaches for any particular period of structure at fixed base condition. Marginal variation in $V_{B(\text { col })} / V_{B(\text { fixed })}$ and $V_{B(\text { pile })} / V_{B(\text { fixed })}$ are also observed for the three different approaches in case of linear and parabolic variation of $E_{s}(z)$ with depth. Henceforth, analysis results are discussed considering a single approach provided by Gazetas and Dobry (1984) for the brevity of this paper. It may be mentioned that Gazetas and Dobry (1984) approach is well accepted and mostly used in various studies (Ramachandran 2005; Badoni, Makris 1996; Makris, Gazetas 1992). Figures 7(a), (c) and (e) present variation of $V_{B(\mathrm{col})} / V_{B(\text { fixed })}$ or very soft, soft and moderately stiff while Figures 7(b), (d) and (f) show results of $V_{B(\text { pile })} / V_{B(\text { fixed })}$ for same three soil types, respectively, considering linear variation of lateral subgrade modulus $E_{s}(z)$ with depth and for three different $L / d$ ratios of pile. Figures 8 and 9 present the similar results for constant and parabolic variation of $E_{s}(z)$ with depth respectively. For all the cases, it is observed that the normalized shear at column $\left(V_{B(\text { col })} / V_{B(\text { fixed })}\right)$ generally exhibits a value very close to unity implying that column shear does not appreciably alter due to soil structure interaction effect 


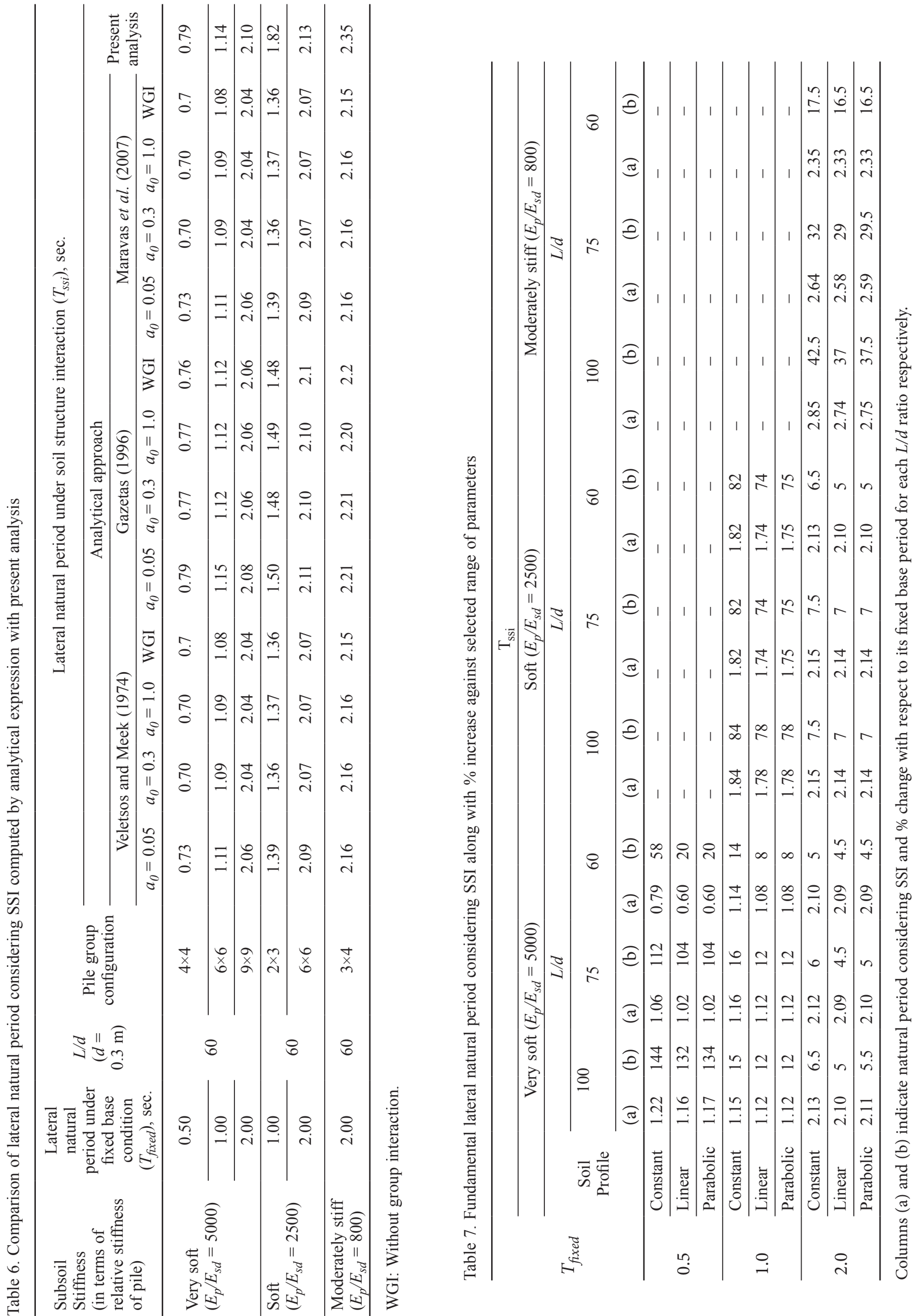


as compared to what is obtained in fixed base condition. However, the trend seems to be little different for the lateral shear carried by piles which is evident from Figures 7-9 (b), (d) and (f). These results show that the shear forces in the pile in very soft soil may be as high as 1.7 times the base shear obtained at fixed base condition (Figs 7(b), 8(b) and 9(b)) in case of long period structure for three different $L / d$ ratios. This is possibly due to the additional inertia force attracted by foundation mass. However, this increase in shear forces in the pile seems to be relatively reduced for moderately stiff soil as is evident from the Figure 7(f). This is possibly due to relatively higher lengthening of period in soil of higher stiffness. Similar trend is also observed in case of constant and parabolic soil $E_{s}(z)$, which is evident from Figures 8(b), (d), (f) and Figures 9(b), (d), (f).

Figures 7 to 9 also exhibit that normalized shear in columns as well as in piles are marginally influenced by the nature of depth wise variation of soil subgrade modulus, since fundamental period of the system incorporating SSI $\left(T_{s s i}\right)$ is observed almost same for various depth wise variation of soil $E_{s}(z)$. This implies overall stiffness of soil-pile raft-structure system remain unaltered due to such variations. Period of the system incorporating SSI $\left(T_{S S i}\right)$ is observed almost the same for various depth wise variation of $E_{s}(z)$. Period of the system incorporating SSI $\left(T_{s s i}\right)$ is observed almost the same for various depth wise variation of $E_{s}(z)$. This implies overall stiffness of soilpile raft-structure system remain unaltered due to such variations. The effect of $L / d$ ratios of pile on column and pile responses seem to be marginal as is evident from the same figures. In fact, the $L / d$ ratios considered for the analysis represent flexible pile. Makris and Gazetas (1992) stated that effect of $L / d$ ratio has no influence on dynamic response of piles in case of flexible piles, rather active length of pile governs the response. In the present analysis, active length of pile is observed to be the same irrespective of all $L / d$ ratios for a particular soil stiffness. Hence, marginal variation is observed for various $L / d$ ratios of pile. However, the observation that the shear transferred to the piles may be substantially higher than what is estimated from fixed base condition may have serious implications in seismic design of piles. Such observations are also attempted to be validated in a limited form by considering a MDOF idealisation of structure which seem to represent a more realistic response of the system. It is observed that a 4-storeyed building supported by a $3 \times 3$ pile group in very soft soil experiences a normalised ratio of $V_{B(\text { col })} / V_{B(\text { fixed })}$ and $V_{B(\text { pile })} /$ $V_{B(\text { fixed })}$ in the order of 1.20 and 1.80 respectively. These parameters obtained through SDOF modeling for $0.5 \mathrm{sec}$ period are about 1.10 and 1.40 respectively for all three soil profiles which are close to what is observed from MDOF system. Further, this limited study indicates that pile experiences relatively higher response compared to SDOF idealization of structure, while the phenomenon seems to be similar in both the idealization. The in general phenomenon observed in this study is attempted to explain with the help of an exemplary case.

\section{Example case study}

A five storeyed building having period $\left(T_{\text {fixed }}\right)$ of $0.5 \mathrm{sec}$ at fixed base condition is considered herein. Foundation design steps for the building are presented considering fixed base condition and SSI as well. Numbers of piles are calculated based on total weight of superstructure considering the fact that such five storey building has fundamental period of $0.5 \mathrm{sec}$, a single storey superstructure with gravity loading as that of a five storey one, with plan area $8.5 \times 8.5 \mathrm{~m}$ is considered by adjusting its lateral stiffness at fixed base condition to $0.5 \mathrm{sec}$. Other details about the structure are presented in Table 8. SSI is incorporated considering piled raft foundation as outlined earlier under fixed base condition as well as considering SSI. The base shear forces are estimated for both the cases. $V_{B(f i x e d)}$ is estimated using design response spectrum suggested by various codes, namely, Indian standard (BIS 1893-Part-I 2002; BIS 1893, 1984), Uniform building code (UBC, 1997) and Eurocode 8-Part 1 (1998) for analysis purpose. Likewise, $V_{B(c o l)}$ and $V_{B(p i l e)}$ are calculated considering soil-pile raft structure system. Summary of results are presented in Table 9(a).
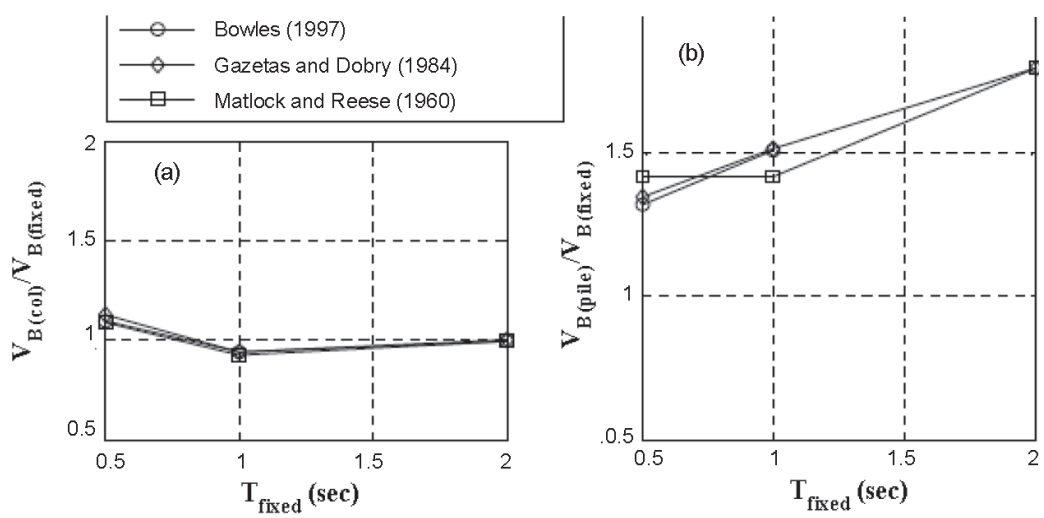

Fig. 6. Comparison responses of three different approaches to determine $k_{h}$ for very soft soil, $L / d=60$ and constant soil profile: a) normalised column shear; b) normalised pile head shear 


\subsection{Check for pile design under horizontal shear}

Lateral yielding capacity of a single pile is calculated based on soil yield displacement criterion. The yield displacement of soil is calculated as follows (Hsiung 2003):

$$
u^{*}=20 \xi_{c} d,
$$

where: $u^{*}=$ the yield displacement; $\xi_{\theta}$ represents strain at fifty percent of ultimate lateral load $=0.01$ for normally consolidated clays and diameter of pile. Therefore, $u^{*}$ is estimated as $60 \mathrm{~mm}$.

Lateral displacement of fixed head single pile can be calculated based on specified lateral load as suggested by IS: 2911 Part 1/Sec 4 (1984), as follows.

$$
Y=\frac{Q\left(L_{1}+L_{f}\right)^{3}}{12 E_{p} I_{p}}
$$

where: $Y$ is displacement at pile head; $Q$ is the horizontal load at pile head; $L_{1}$ is the point of application of load above ground surface; $L_{f}$ is the depth of fixity below ground surface; $E_{p}$ is the Young's modulus of pile; and $I_{p}$ is the area moment of inertia. Horizontal yielding load of a fixed head pile can be computed after rearranging the Eqn (12) and putting $Y=u^{*}$ :

$$
H_{y}=\frac{12 E_{p} I_{p} u^{*}}{\left(L_{1}+L_{f}\right)^{3}} .
$$

Value of $L_{f} / R$ can be estimated for the given $L_{1}$ value using IS: 2911 Part 1/Sec 4 (1984). $R$ is a non-dimensional parameter which can be calculated as follows:
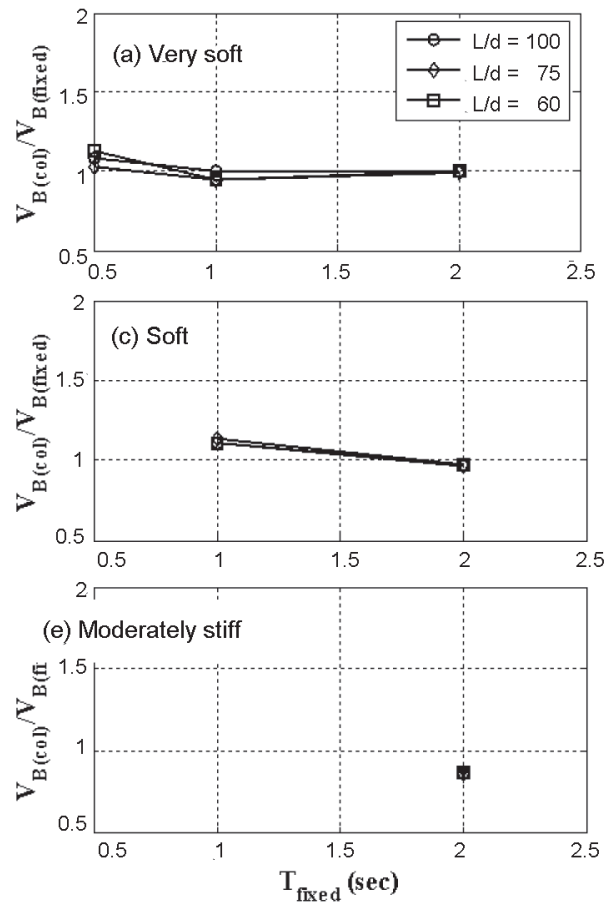

$$
R=\sqrt[4]{\frac{E_{p} I_{p}}{k_{2}}}=33.05
$$

where $k_{2}$ is a stiffness parameter given in IS: 2911 Part $1 / \operatorname{Sec} 4$ (1984). Considering $k_{2}=7.905 \mathrm{kN} / \mathrm{m}^{2}, E_{p}=$ $2.17 \times 10^{7} \mathrm{kN} / \mathrm{m}^{2}, I_{p}=3.98 \times 10^{-4} \mathrm{~m}^{4}$.

$L_{1}=0$, value of $R=33.05 \mathrm{~m}$ and $L_{f}=5.75 \mathrm{~m}$. Therefore, for $u^{*}=60 \mathrm{~mm}, H_{y}=33 \mathrm{kN}$.

Assuming uniform distribution of base shear among all piles in a group, lateral force on single pile is calculated and compared with lateral yielding load of single pile as presented in Table 9(b) as per various seismic codes. In fixed base condition, estimated lateral load in each pile comes to be less than pile capacity, $H_{y}$, while it becomes considerably larger than $H_{y}$ when SSI is incorporated. Thus, ignoring SSI may lead to an unsafe pile design.

\section{Effect of uncertainty in input soil parameters}

Present study considers different soil parameters pertaining to soil stiffness, variation of soil modulus with respect to depth and different approaches to find $k_{h}(z)$ which results in uncertainty in soil subgrade modulus. A total number of 27 values $k_{h}(z)$ is adopted as input modulus with respect to depth and different approaches to find $k_{h}(z)$ which results in uncertainty in soil subgrade modulus. Uncertainty of $k_{h}(z)$ is obtained using routine statistical analysis and presented in Table 10. The uncertainties of $V_{B(\text { col })} / V_{B(\text { fixed })}$ and $V_{B(\text { pile })} / V_{B(f i x e d)}$ are also estimated based on 27 cases and presented in Table 10 indicates input variability i.e. coefficient of variation $(\mathrm{COV})$ of $k_{h}(z)$
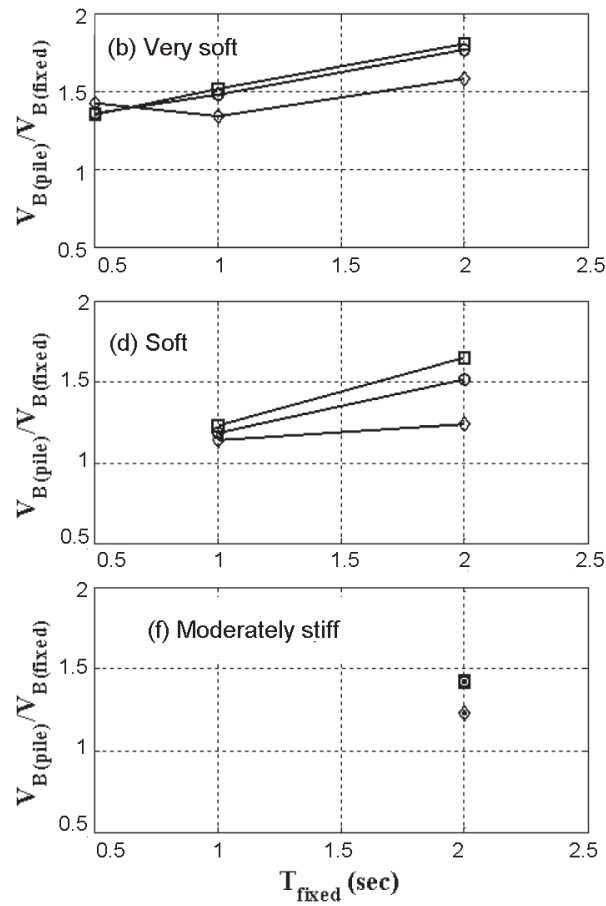

Fig. 7. Variations of normalised base shear for linear variation of soil modulus for different $L / d$ ratios: a) $V_{B(\text { col })} / V_{B(\text { fixed })}$ versus $T_{\text {fixed }}$ for very soft soil; b) $V_{B(\text { pile })} / V_{B(\text { fixed })}$ versus $T_{\text {fixed }}$ for very soft soil; c) $V_{B(\text { col })} / V_{B(\text { fixed })}$ versus $T_{\text {fixed }}$ for soft soil; d) $V_{B(\text { pile })} /$ $V_{B(\text { fixed })}$ versus $T_{\text {fixed }}$ for soft soil; e) $V_{B(\text { col })} / V_{B(f i x e d)}$ versus $T_{\text {fixed }}$ for moderately stiff soil; f) $V_{B(\text { pile })} / V_{B(\text { fixed })}$ versus $T_{\text {fixed }}$ for moderately stiff soil 

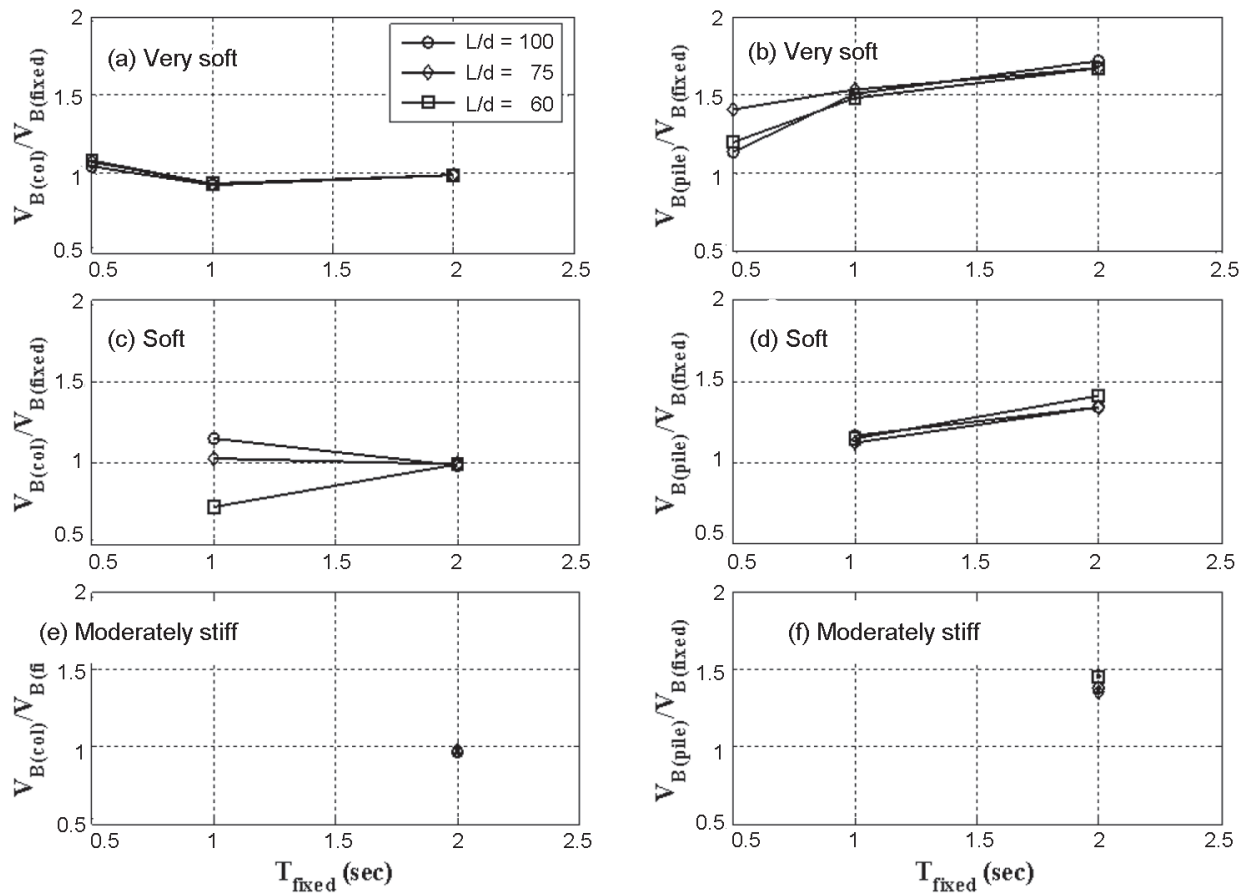

Fig. 8. Variations of normalised base shear for constant soil modulus for different $L / d$ ratios: a) $V_{B(\text { col })} / V_{B(\text { fixed })}$ versus $T_{\text {fixed }}$ for very soft soil; b) $V_{B(\text { pile })} / V_{B(\text { fixed) }}$ versus $T_{\text {fixed }}$ for very soft soil; c) $V_{B(\text { col })} / V_{B(\text { fixed) }}$ versus $T_{\text {fixed }}$ for soft soil; d) $V_{B(\text { pile })} / V_{B(\text { fixed })}$ versus $T_{\text {fixed }}$ for soft soil; e) $V_{B(\text { col })} / V_{B(\text { fixed })}$ versus $T_{\text {fixed }}$ for moderately stiff soil; f) $V_{B(\text { pile })} / V_{B(f i x e d)}$ versus $T_{\text {fixed }}$ for moderately stiff soil
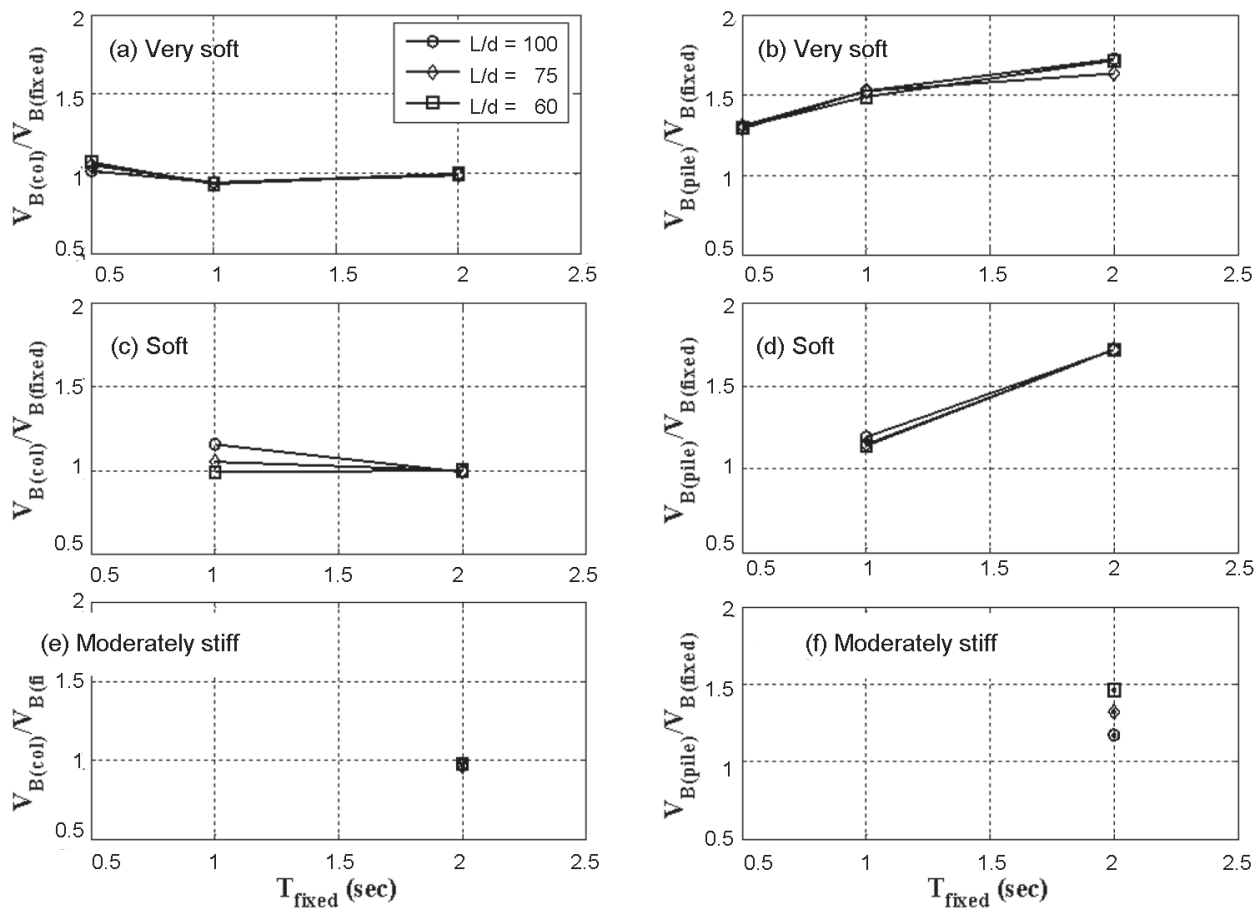

Fig. 9. Variations of normalised base shear for parabolic variation of soil modulus for different $L / d$ ratios: a) $V_{B(\text { col })} / V_{B(f i x e d)}$ versus $T_{\text {fixed }}$ for very soft soil; b) $V_{B(\text { pile })} / V_{B(\text { fixed })}$ versus $T_{\text {fixed }}$ for very soft soil; c) $V_{B(\text { col })} / V_{B(\text { fixed) }}$ versus $T_{\text {fixed }}$ for soft soil; d) $V_{B(\text { pile })} / V_{B(\text { fixed })}$ versus $T_{\text {fixed }}$ for soft soil; e) $V_{B(\text { col })} / V_{B(\text { fixed })}$ versus $T_{\text {fixed }}$ for moderately stiff soil; f) $V_{B(\text { pile })} / V_{B(\text { fixed })}$ versus $T_{\text {fixed }}$ for moderately stiff soil 
Table 8. Input parameters for example case study

\begin{tabular}{ll}
\hline Parameters & \multicolumn{1}{c}{ Value } \\
\hline Plan area of bare frame structure & $8.5 \times 8.5 \mathrm{~m}$ \\
\hline Total height of building considering $3.5 \mathrm{~m}$ height for each storey & $35 \mathrm{~m}$ \\
\hline Intensity of gravity loading & $8.0 \mathrm{kN} / \mathrm{m}^{2}$ \\
\hline Size of column & $0.5 \times 0.5 \mathrm{~m}$ \\
\hline Number of columns supporting the slab & 4 \\
\hline Plan area of a raft & $10 \times 10 \mathrm{~m}$ \\
\hline Raft thickness & $0.075 \mathrm{~m}$ \\
\hline Soil stiffness & Very soft $\left(E_{p} / E_{s d}=5000\right)$ \\
\hline Pile group designed as per vertical load & $4 \times 4$ \\
\hline Diameter of each pile $(d)$ & $0.3 \mathrm{~m}$ \\
\hline Spacing to diameter ratio $(S / d)$ & 3.0 \\
\hline Length to diameter ratio $(L / d)$ & 60 \\
\hline Depth-wise variation of $E_{s}(\mathrm{z})$ & Constant \\
\hline
\end{tabular}

which is as high as $117 \%$. However, COVS of $V_{B(\mathrm{col})}$ $V_{B(\text { fixed })}$ and $V_{B(\text { pile })} / V_{B(\text { fixed })}$ are $12 \%$ and $20 \%$ respectively, which are relatively lesser than input uncertainty. This clearly indicates that variability of $V_{B(\text { col })} / V_{B(\text { fixed })}$ and $V_{B(\text { pile })} / V_{B(\text { fixed })}$ are relatively much less compared to the variability of input parameters.

\section{Summary and conclusions}

Present study highlights the significance of soil structure interaction in seismic design of structures, supported by piled-raft foundation. The study leads to the following broad conclusions.

1. Simple model consisting of piles supported by distributed lateral springs with their stiffness derived from simple consideration of subgrade modulus seem to capture the effect of SSI with reasonable accuracy while compared with other well accepted analytical formulations for computing lengthened fundamental periods due to SSI effect:

2. Lateral fundamental period of pile supported raftsuperstructure system exhibits lengthening, which seems to be maximum in case of stiff structure supported by slender piles. It may even increase up to about $150 \%$ for structure supported by pile group having $L / d=100$ in very soft soil and constant subgrade modulus with depth when $T_{\text {fixed }}=0.5 \mathrm{sec}$. Number of piles in a group due to change in stiffness of soil (i.e. $E_{p} / E_{s d}$ ) plays a major role in period lengthening of soil-pile raft-superstructure system. However, such inference is valid for constant $S / d$ ratio. Overall stiffness of soil-pile system reduces in case of moderately stiff soil due to

3. the involvement of less number of piles, hence such system exhibits a tendency of further lengthening of period as compared to relatively softer counterparts. Though the maximum lengthening still occurs for very soft soil as mentioned earlier.
4. The study shows that SSI has marginal effect on seismic column shear while it may lead to considerable increase in seismic lateral force in piles because of the additional inertia force contributed by heavy mass of the foundation, which is not accounted for in the fixed base condition. This increase may go up to a maximum extent of about $70 \%$ even for a long period structure $\left(T_{f i x e d}=2.0 \mathrm{sec}\right)$ in very soft soil, irrespective of any depth wise variation of subgrade modulus. Similar response is observed for MDOF idealization of structure.

5. A limited statistical study indicates that the response quantities observed in column as well as in pile incorporating SSI exhibits relatively a lesser variability against the wide range of input variability. Subgrade modulus of soil is acting as an input variability which indicates the major source of uncertainty. However, a detailed probabilistic study is required to conclude this issue which is left for future work.

Further, various curves related to the responses of column and pile presented herein may be helpful for any case specific design. These curves may also be useful to get a broad idea about the role of SSI in the design of column and pile under seismic loading. However, present study mainly intends to show the importance of soil-pile raft-structure interaction as a whole instead of fixed base consideration on distribution of seismic design forces at structural and foundation elements in case of piled raft supported structure but with a limitation of general design guidelines. The effect of frequency dependent group interaction appears to be marginal, at least for the considered case studies. However, the effect of dynamic interaction factor on overall response of the system in general may be investigated in detail as a future scope of study. Similarly, a further rigorous study focusing on the issue of damping may also provide interesting input in this regard. 
Table 9. Results for example case study

(a) Summary of base shear values

\begin{tabular}{lccccc}
\hline \multirow{2}{*}{$\begin{array}{l}\text { Support } \\
\text { condition }\end{array}$} & $\begin{array}{c}\text { Shear at different } \\
\text { element }\end{array}$ & $\begin{array}{c}\text { IS1893 (1984) } \\
\text { (THA) }\end{array}$ & $\begin{array}{c}\text { IS1893 (2000) } \\
\text { (ESA) }\end{array}$ & $\begin{array}{c}\text { UBC (1997) } \\
\text { (ESA) }\end{array}$ & $\begin{array}{c}\text { Eurocode-8 Part 1 } \\
(1998) \\
\text { (RSA) }\end{array}$ \\
\hline Fixed base & $V_{B(\text { fixed })}$ & 506 & 518 & 471 & 522 \\
\hline $\begin{array}{l}\text { Incorporating } \\
\text { SSI }\end{array}$ & $V_{B(\text { col })}$ & 568 & 510 & 394 & 606 \\
\hline
\end{tabular}

THA: Time history analysis; ESA: Equivalent static approach; RSA: Response spectrum analysis.

(b) Shear in single pile

\begin{tabular}{|c|c|c|c|c|c|}
\hline \multirow[b]{2}{*}{ Support condition } & \multicolumn{4}{|c|}{ Base Shear acting at single pile head $(\mathrm{kN})$} & \multirow[b]{2}{*}{ Remarks } \\
\hline & $\begin{array}{c}\text { IS1893 (1984) } \\
\text { (THA) }\end{array}$ & $\begin{array}{c}\text { IS1893 (2000) } \\
\text { (ESA) }\end{array}$ & $\begin{array}{c}\text { UBC (1997) } \\
\quad(\text { ESA) }\end{array}$ & $\begin{array}{l}\text { Eurocode-8 } \\
\text { Part } 1 \text { (1998) } \\
\quad(\text { RSA })\end{array}$ & \\
\hline Fixed base & $31.63\left(<H_{y}\right)$ & $32.4\left(<H_{y}\right)$ & $29.40\left(<H_{y}\right)$ & $32.63\left(<H_{y}\right)$ & \multirow{2}{*}{$\begin{array}{l}\text { Lateral capacity of pile } \\
\text { corresponding to yield } \\
\text { displacement } \\
\left(H_{y}\right)=33 \mathrm{kN}\end{array}$} \\
\hline Incorporating SSI & $42.6\left(>H_{y}\right)$ & $47.6\left(>H_{y}\right)$ & $38.18\left(>H_{y}\right)$ & $46.2\left(>H_{y}\right)$ & \\
\hline
\end{tabular}

THA: Time history analysis; ESA: Equivalent static approach; RSA: Response spectrum analysis.

\section{Acknowledgement}

The authors gratefully acknowledge the contributions of reviewers for their critical review comments which helped to upgrade the paper to a better extent.

\section{References}

Applied Technology Council. 1978. Tentative provisions for the development of seismic regulations of buildings: a cooperative effort with the design profession, building code interests and the research community. National Bureau of Standards, Supt. of Docs, Washington DC.

Applied Technology Council. 1996. Seismic evaluation and retrofit of concrete buildings. California Seismic Safety Commission, California, Vol. 1.

Badoni, D.; Makris, M. 1996. Nonlinear response of single piles under lateral inertial and seismic loads, Journal of Soil Dynamics and Earthquake Engineering 15(1): 29-43. http://dx.doi.org/10.1016/0267-7261(95)00027-5

Banerjee, P. K.; Davies, T. G. 1978. The linear behavior of axially and laterally loaded single piles embedded in nonhomogenous soils, Geotechnique 28(3): 309-326. http://dx.doi.org/10.1680/geot.1978.28.3.309

Bhattacharya, K.; Dutta, S. C.; Dasgupta, S. 2004. Effect of soil-flexibility on dynamic behaviour of building frames on raft foundation, Journal of Sound and Vibration 274(1-2): 111-135. http://dx.doi.org/10.1016/S0022-460X(03)00652-7

Blaney, G. W.; Kausel, E.; Roesset, J. M. 1976. Dynamic stiffness of piles, in Proc. of Second International Conference on Numerical Methods in Geomechanics, 1976, ASCE Blacksburg, Virginia, 1001-1012.

Boulanger, R. W.; Curras, C. J.; Kutter, B. L.; Wilson, W. D.; Abghari, A. A. 1999. Seismic soil-pile-structure interaction experiments and analyses, Journal of Geotechnical and
Geoenvironmental Engineering ASCE 125(9): 750-759.

http://dx.doi.org/10.1061/(ASCE)1090-0241(1999)125:9(750)

Bowles, J. E. 1997. Foundation analysis and design. $6^{\text {th }}$ ed. Singapore: McGraw-Hill Book Company. 1175 p.

Budhu, M.; Davies, G. T. 1988. Analysis of laterally loaded piles in soft clays, Journal of Geotechnical Engineering 114(1): 21-39.

http://dx.doi.org/10.1061/(ASCE)0733-9410(1988)114:1(21)

Bureau of Indian Standards (BIS). 1984. Indian standard criteria for earthquake resistant design of structures. New Delhi, India, IS: 1893.

Bureau of Indian Standards (BIS). 2002. Indian standard criteria for earthquake resistant design of structures. New Delhi, India, IS: 1893: Part I.

Chopra, A. K. 2008. Dynamics of structures: theory and applications to earthquake engineering. Pearson Prentice Hall. $876 \mathrm{p}$

Clough, W. R.; Penzien, J. 1995. Dynamics of structures. $3^{\text {rd }}$ ed. Comp \& Struct. 126 p.

Curras, J. C.; Boulanger, W. R.; Kutter, B. L.; Wilson, D. W. 2001. Dynamic experiments and analysis of a pile-groupsupported structure, Journal of Geotechnical and Geoenvironmental Engineering ASCE 127(7): 585-596.

http://dx.doi.org/10.1061/(ASCE)1090-0241(2001)127:7(585)

Dobry, R.; Gazetas, G. 1988. Simplified method for dynamic stiffness and damping of floating pile group, Geotechnique 38(4): 557-574.

http://dx.doi.org/10.1680/geot.1988.38.4.557

Douglas, D. J.; Davis, E. H. 1964. The movement of buried footings due to moment and horizontal load and the movement of anchor plates, Geotechnique 14(2): 115-132. http://dx.doi.org/10.1680/geot.1964.14.2.115

Dutta, S. C.; Bhattacharya, K.; Roy, R. 2004. Response of lowrise buildings under seismic ground excitation incorporating soil-structure interaction, Journal of Soil Dynamics and Earthquake Engineering 24(12): 893-914. http://dx.doi.org/10.1016/j.soildyn.2004.07.001 
Table 10. Results for statistical analysis determined from 27 input values of of $k_{h}(z), \quad V_{B(\text { col })} / V_{B(\text { fixed })}$ and $V_{B(\text { pile })} / V_{B(\text { fixed })}$

\begin{tabular}{|c|c|c|c|c|c|c|c|c|}
\hline $\begin{array}{c}\text { Empirical } \\
\text { expression } \\
\text { used for } \\
\text { estimating } \\
k_{h(z)}\end{array}$ & $\begin{array}{c}\text { Soil } \\
\text { stiffness } \\
\text { (in terms of } \\
\text { relative stiffness } \\
\text { of pile) }\end{array}$ & $\begin{array}{c}\text { Variation } \\
\text { of } E_{s}(z) \text { with } \\
\text { depth }\end{array}$ & $\begin{array}{l}\text { Average value } \\
\text { of } k_{h}(z) \text { for } \\
\text { depth } 10 \mathrm{~m} \\
\text { below ground } \\
\text { surface }(\mathrm{kN} / \\
\left.\mathrm{m}^{2} / \mathrm{m}\right)\end{array}$ & $\begin{array}{l}\text { Statistical } \\
\text { features }\end{array}$ & $\begin{array}{c}\text { Normalised } \\
\text { Column } \\
\text { shear, } \\
V_{B(\text { col })} \\
V_{B \text { (fixed) }}\end{array}$ & $\begin{array}{l}\text { Statistical } \\
\text { features }\end{array}$ & $\begin{array}{c}\text { Normalised } \\
\text { Pile shear, } \\
V_{B(\text { pile })} \\
V_{B(\text { fixed })}\end{array}$ & $\begin{array}{c}\text { Statistical } \\
\text { features }\end{array}$ \\
\hline \multirow{9}{*}{$\begin{array}{l}\text { Bowles } \\
\text { (1997) }\end{array}$} & \multirow{3}{*}{$\begin{array}{l}\text { Very soft } \\
\left(E_{p} / E_{s d}=5000\right)\end{array}$} & Constant & 5784 & \multirow{27}{*}{ 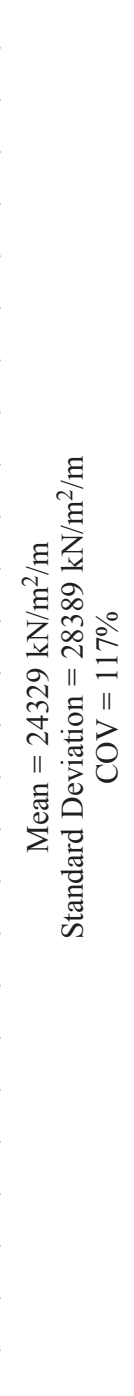 } & 0.99 & \multirow{27}{*}{ 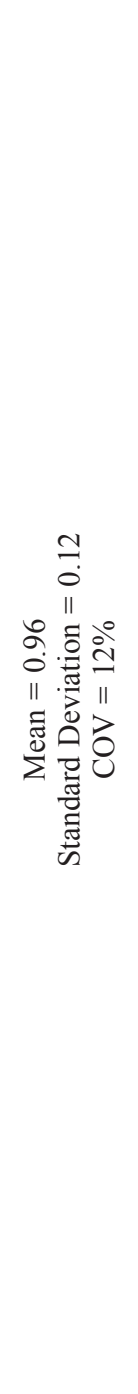 } & 1.01 & \multirow{27}{*}{ 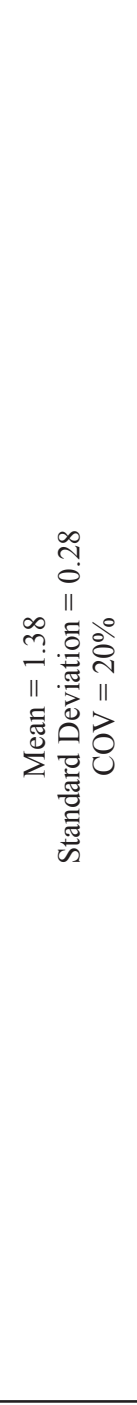 } \\
\hline & & linear & 7364 & & 1 & & 1.01 & \\
\hline & & Parabolic & 6682 & & 1 & & 1.01 & \\
\hline & \multirow{3}{*}{$\begin{array}{l}\text { Soft } \\
\left(E_{p} / E_{s d}=2500\right)\end{array}$} & Constant & 2727 & & 1.00 & & 1.80 & \\
\hline & & linear & 4483 & & 0.99 & & 1.01 & \\
\hline & & Parabolic & 5953 & & 0.99 & & 1 & \\
\hline & \multirow{3}{*}{$\begin{array}{l}\text { Moderately stiff } \\
\left(E_{p} / E_{s d}=800\right)\end{array}$} & Constant & 6000 & & 1.00 & & 1.80 & \\
\hline & & linear & 23833 & & 0.99 & & 1.67 & \\
\hline & & Parabolic & 12101 & & 0.99 & & 1.71 & \\
\hline \multirow{9}{*}{$\begin{array}{l}\text { Matlock } \\
\text { and Reese } \\
(1960)\end{array}$} & \multirow{3}{*}{$\begin{array}{l}\text { Very soft } \\
\left(E_{p} / E_{s d}=5000\right)\end{array}$} & Constant & 10957 & & 1.00 & & 1.64 & \\
\hline & & linear & 14054 & & 1 & & 1.01 & \\
\hline & & Parabolic & 12692 & & 1 & & 1.01 & \\
\hline & & Constant & 7723 & & 0.99 & & 1.51 & \\
\hline & $\begin{array}{l}\text { Sott } \\
\left(E_{E} / E_{\text {o }}=2500\right)\end{array}$ & linear & 14933 & & 1 & & 1.72 & \\
\hline & & Parabolic & 19830 & & 0.99 & & 1 & \\
\hline & & Constant & 12000 & & 0.97 & & 1.64 & \\
\hline & $\begin{array}{l}\text { Moderately stiff } \\
(F / F=800)\end{array}$ & linear & 47666 & & 0.99 & & 1.4 & \\
\hline & & Parabolic & 24203 & & 0.99 & & 1.72 & \\
\hline \multirow{9}{*}{$\begin{array}{l}\text { Gazatas } \\
\text { and Dobry } \\
(1984)\end{array}$} & \multirow{3}{*}{$\begin{array}{l}\text { Very soft } \\
\left(E_{p} / E_{s d}=5000\right)\end{array}$} & Constant & 21256 & & 0.98 & & 1.45 & \\
\hline & & linear & 25814 & & 0.97 & & 1.37 & \\
\hline & & Parabolic & 24158 & & 0.97 & & 1.36 & \\
\hline & \multirow{3}{*}{$\begin{array}{l}\text { Soft } \\
\left(E_{p} / E_{s d}=2500\right)\end{array}$} & Constant & 25607 & & 0.97 & & 1.45 & \\
\hline & & linear & 29838 & & 0.97 & & 1.37 & \\
\hline & & Parabolic & 39624 & & 0.98 & & 1.42 & \\
\hline & \multirow{3}{*}{$\begin{array}{l}\text { Moderately stiff } \\
\left(E_{p} / E_{s d}=800\right)\end{array}$} & Constant & 36000 & & 0.87 & & 1.42 & \\
\hline & & linear & 143000 & & 0.38 & & 1.45 & \\
\hline & & Parabolic & 72611 & & 0.98 & & 1.46 & \\
\hline
\end{tabular}

Dutta, S. C.; Das, P. K. 2002. Inelastic seismic response of code-designed reinforced concrete in elastic seismic response of code-designed reinforced concrete asymmetric buildings with strength degradation, Engineering Structures 24(10): 1295-1314.

http://dx.doi.org/10.1016/S0141-0296(02)00062-7

Dutta, S. C.; Bhattacharya, K.; Roy, R. 2009. Effect of flexibility of foundations on its seismic stress distribution, Journal of Earthquake Engineering 13(1): 22-49.

http://dx.doi.org/10.1080/13632460802211974

Eurocode 8-Part 1 1998. Design of Structures for Earthquake Resistance. Commission of the European Communities and the European Committee for Standardization (CEN), UK.

FEMA 356. 2000. Prestandard and commentary for the seismic rehabilitation of buildings. Federal Emergency Management Agency, Washington, DC, U.S.A.
FEMA 440. 2005. Improvement of nonlinear static seismic analysis procedures. Federal Emergency Management Agency, Washington, DC, U.S.A.

Gazetas, G. 1984. Seismic response of end-bearing single piles, Journal of Soil Dynamics and Earthquake Engineering 3(2): 82-93.

http://dx.doi.org/10.1016/0261-7277(84)90003-2

Gazetas, G. 1991. Formulas and charts for impedances of surface and embedded foundations, Journal of Geotechnical Engineering ASCE 117(9): 1363-1381.

http://dx.doi.org/10.1061/(ASCE)0733-9410(1991)117:9(1363)

Gazetas, G. 1996. Soil dynamics and earthquake engineering case studies. Athens: Simeon Publications (in Greek).

Gazetas, G.; Dobry, R. 1984. Horizontal response of piles in layered soils, Journal of Geotechnical Engineering ASCE 109(8): 1063-1081. 
Gazetas, G.; Fan, K.; Kaynia, A. 1993. Dynamic response of pile groups with different configurations, Journal of Soil Dynamics and Earthquake Engineering 12(4): 239-257. http://dx.doi.org/10.1016/0267-7261(93)90061-U

Gazetas, G.; Fan, K.; Kaynia, A.; Kausel, E. 1991. Dynamic interaction factors for floating pile groups, Journal of Geotechnical Engineering ASCE 117(10): 1531-1548.

http://dx.doi.org/10.1061/(ASCE)0733-9410(1991)117:10(1531)

Gazetas, G.; Makris, N. 1991. Dynamic pile-soil-pile interaction. Part I: analysis of axial vibration, Earthquake Engineering and Structural Dynamics 20(2): 115-132. http://dx.doi.org/10.1002/eqe.4290200203

Guin, J.; Banerjee, P. K. 1998. Coupled soil-pile-structure interaction analysis under seismic excitation, Journal of Structural Engineering ASCE 124(4): 434-444.

http://dx.doi.org/10.1061/(ASCE)0733-9445(1998)124:4(434)

Hall, F. J. 1984. Forced vibration and earthquake behaviour of an actual pile foundation, Journal of Soil Dynamics and Earthquake Engineering 3(2): 94-101. http://dx.doi.org/10.1016/0261-7277(84)90004-4

Hsiung, M. Y. 2003. Theoretical elastic-plastic solution for laterally loaded piles, Journal of Geotechnical and Geoenvironmental Engineering ASCE 129(6): 475-480.

http://dx.doi.org/10.1061/(ASCE)1090-0241(2003)129:6(475)

Japan Road Association (JSCE). 2000. Earthquake resistant design codes in Japan - 1996 Seismic design specifications of Highway bridges. Japan.

Kaynia, M. A.; Kausel, E. 1991. Dynamics of piles and pile groups in layered soil media, Journal of Soil Dynamics and Earthquake Engineering 10(8): 386-401. http://dx.doi.org/10.1016/0267-7261(91)90053-3

Makris, N.; Gazetas, G. 1992. Dynamic pile-soil-pile interaction. Part II: lateral and seismic response, Earthquake Engineering and Structural Dynamics 21(2): 145-162. http://dx.doi.org/10.1002/eqe.4290210204

Maravas, A.; Mylonakis, G.; Karabalis, D. 2007. Dynamic characteristics of simple structures on piles and footings, in Proceedings of the $4^{\text {th }}$ International Conference on Earthquake Geotechnical Engineering, 2007, Thessaloniki, Greece, Paper no. 1672.

Matlock, H.; Reese, L. C. 1960. Generalized solutions for laterally loaded piles, Journal of Soil Mechanics and Foundation Engineering ASCE 86: 63-91.

Mylonakis, G.; Gazetas, G. 1999. Lateral vibration and internal forces of grouped piles in layered soil, Journal of Geotechnical and Geoenvironmental Engineering ASCE 125(1): 16-25.

http://dx.doi.org/10.1061/(ASCE)1090-0241(1999)125:1(16)

Mylonakis, G.; Gazetas, G. 2000. Seismic soil-structure interaction: beneficial or detrimental?, Journal of Earthquake Engineering 4(3): 277-301. http://dx.doi.org/10.1142/S1363246900000175

Mylonakis, G.; Gazetas, G. 2002. Kinematic soil response to vertical P-wave seismic excitation, Journal of Geotechnical and Geoenvironmental Engineering ASCE 128(10): 860-867.

http://dx.doi.org/10.1061/(ASCE)1090-0241(2002)128:10(860)

Naggar, M. H. E.; Novak, M. 1996. Nonlinear analysis for dynamic lateral pile response, Journal of Soil Dynamics and Earthquake Engineering 15(4): 233-244. http://dx.doi.org/10.1016/0267-7261(95)00049-6

NCHPR 461. 2001. Static and Dynamic lateral loading of pile groups. National Cooperative Highway Research Program, Washington, DC, U.S.A.

Nikolaou, S.; Mylonakis, G.; Gazetas, G.; Tazoh, T. 2001. Kinematic pile bending during earthquakes: analysis and field measurements, Geotechnique 51(5): 425-440. http://dx.doi.org/10.1680/geot.2001.51.5.425
Nogami, T.; Novak, M. 1980. Coefficients of soil reaction to pile vibration, Journal of Geotechnical Engineering ASCE 106(GT5): 565-569.

Novak, M. 1974. Dynamic stiffness and damping of piles, Canadian Geotechnical Journal 11(4): 574-598. http://dx.doi.org/10.1139/t74-059

Novak, M.; Aboul-Ella, F. 1978. Impedance function of piles in layered media, Journal of the Engineering Mechanics division ASCE 104(EM6): 643-661.

Ohsaki, Y.; Iwasaki, R. 1973. On dynamic shear moduli and Poisson's ratio of soil deposits, Soils and Foundations 13(4): 61-73. http://dx.doi.org/10.3208/sandf1972.13.4 61

Ohta, T.; Uchiyama, S.; Niwa, M.; Ueno, K. 1980. Earthquake response characteristics of structure with pile foundation on soft subsoil layer and its simulation analysis, in Proc. of $7^{\text {th }}$ World Conference on Earthquake Engineering, 1980, Istanbul, Turkey, 467-470.

Pender, J. M.; Satyawan, P. 1996. Gapping effects during cyclic lateral loading of piles in clay, in Proc. of the World Conference on Earthquake Engineering, 1996, Mexico, 23-28.

Poulos, H. G. 2001. Piled raft foundations: design and applications, Geotechnique 51(2): 95-113. http://dx.doi.org/10.1680/geot.2001.51.2.95

Poulos, H. G.; Davis, E. H. 1980. Pile foundation analysis and design. Canada: John Willey and Sons. 397 p.

Ramachandran, J. 2005. Analysis of pile foundations under seismic loading. Final report. CBE Institute, USA.

Randolph, M. F. 1981. The response of flexible piles to lateral loading, Geotechnique 31(2): 247-259. http://dx.doi.org/10.1680/geot.1981.31.2.247

Reese, L. C. 1977. Laterally loaded piles: programme documentation, Journal of Geotechnical Engineering ASCE 103(GT4): 287-305.

Reese, L. C.; Matlock, H. 1956. Non-dimensional solutions for laterally loaded piles with soil modulus assumed proportional to depth, in Proc. of the $8^{\text {th }}$ Texas Conference on Soil Mechanics and Foundation Engineering, Spec. pub. 29, Bureau of Eng. Res., University of Texas, Austin.

Roesset, J. M.; Angelides, D. 1980. Dynamic stiffness of piles, in Numerical methods in offshore piling, Institute of Civil Engineers, 75-81.

Rovithis, E. N.; Pitilakis, K. D.; Mylonakis, G. E. 2009. Seismic analysis of coupled soil-pile-structure systems leading to the definition of a pseudo-natural SSI frequency, Journal of Soil Dynamics and Earthquake Engineering 29(6): 1005-1015. http://dx.doi.org/10.1016/j.soildyn.2008.11.005

Roy, R.; Dutta, S. C. 2010. Inelastic seismic demand of lowrise buildings with soil-flexibility, International Journal of Non-linear Mechanics 45(4): 419-432. http://dx.doi.org/10.1016/j.ijnonlinmec.2009.12.014

Satake, N.; Suda, K.; Arakawa, T.; Saraki, A.; Tamura, Y. 2003. Damping evaluation using full-scale data of buildings in Japan, Journal of Structural Engineering ASCE 129(4): $470-477$.

http://dx.doi.org/10.1061/(ASCE)0733-9445(2003)129:4(470)

Tajimi, H. 1969. Dynamic analysis of a structure embedded in an elastic stratum, in Proc. of the $4^{\text {th }}$ World Conference on Earthquake Engineering, 1969, Chile. 17 p.

Veletsos, A. S. 1977. Dynamics of structure-foundation systems. Structural and Geotechnical Mechanics, WJ Hall. New Jersey: Prentice Hall.

Veletsos, A. S.; Meek, J. W. 1974. Dynamic behavior of building - foundation systems, Earthquake Engineering and Structural Dynamics 3(2): 121-138. http://dx.doi.org/10.1002/eqe.4290030203 
Velez, A.; Gazetas G.; Krishnan, R. 1983. Lateral dynamic response of constrained head piles, Journal of Geotechnical Engineering ASCE 109(8): 1063-1081.

http://dx.doi.org/10.1061/(ASCE)0733-9410(1983)109:8(1063)
Yingcai, H. 2002. Seismic response of tall building considering soil-pile-structure interaction, Earthquake Engineering and Engineering Vibration 1(1): 57-64. http://dx.doi.org/10.1007/s11803-002-0008-y

Rajib SAHA. Assistant Professor of Civil Engineering department in National Institute of Technology Agartala, India. Presently pursuing $\mathrm{PhD}$ at School of Infrastructure, Indian Institute of Technology Bhubaneswar as a sponsored research scholar. Prime research interests: dynamic soil-structure interaction and its effect on behaviour of structures, behaviour of piles under static as well as dynamic loading and geotechnical earthquake engineering.

Sekhar Chandra DUTTA. Professor and Head of School of Infrastructure in Indian Institute of Technology Bhubaneswar. PhD in Structural Engineering from Indian Institute of Technology Kanpur, India in the year of 1996. Recently completed prestigious Fulbright-Nehru Senior Research Fellowship program at University of California, Davis. Published around 62 technical papers in various peer reviewed journals of international and national repute and received a few awards in recognition of his research contribution. Main research interest: structural dynamics and earthquake engineering, inelastic seismic behaviour of structures, seismic behaviour of asymmetric structures, vulnerability of non-engineered structures under natural disasters, soil-structure interaction, behaviour of masonry structures under seismic forces.

Sumanta HALDAR. Assistant Professor of School of Infrastructure in Indian Institute of Technology Bhubaneswar. PhD in Geotechnical Engineering from Indian Institute of Science Bangalore, India in the year of 2008. Published around 15 technical papers in various peer reviewed journals of international repute. Main research interests: energy geotechnics, soil-structure interaction, probabilistic geotechnics, geotechnical earthquake engineering, computational geomechanics. 